\title{
PSYCHOLOGICAL INTERVENTION INCLUDING EMOTIONAL FREEDOM TECHNIQUES FOR AN ADULT WITH MOTOR VEHICLE ACCIDENT RELATED POSTTRAUMATIC STRESS DISORDER: A CASE STUDY
}

\author{
Terri Sheldon \\ Clinical Psychologist, Lakeside Rooms, Suite 9 North Building, \\ Robina East Quays Corporate Park, 34-36 Glenferrie Dr, Robina Q4226, Australia
}

Received 2014-06-20; Revised 2014-07-09; Accepted 2014-07-18

\begin{abstract}
Posttraumatic Stress Disorder (PTSD) is a significant public health concern and can have long-term emotional, social and financial consequences for individuals and society. Lifetime prevalence in the general population is estimated at $8 \%$ and rates of exposure to Post-Traumatic Events (PTE) indicate approximately 50 to $65 \%$ have been exposed to at least one PTE in their lives. This indicates that approximately 15 to $25 \%$ of people exposed may also have a diagnosis of PTSD at some time in their life. It is therefore paramount that sufferers receive effective treatment. A case of successful treatment using Emotional Freedom Technique (EFT) combined with more conventional psychological treatment for a woman, DS, suffering from acute PTSD with travel anxiety post a motor vehicle accident is presented. The client's progress was evaluated at baseline and post treatment. After six sessions, over an eight week period, improvements were noted on all identified goals and on all assessment tools such that at post treatment DS no longer met the criteria for PTSD. The case highlights the utility of single case designs to evaluate the clinical decisions made in selection of treatment of PTSD. Theoretical implications of this study are discussed and an evaluation of using EFT in this case is provided.
\end{abstract}

Keywords: Posttraumatic Stress Disorder, Cognitive Behavior Therapy, Emotional Freedom Techniques, Exposure Therapy, Motor Vehicle Accidents

\section{INTRODUCTION}

\subsection{Referral Context and Information}

\subsubsection{Referral Source and Referral Objectives}

DS, a 54 year old woman, was referred by her General Practitioner (GP) in 2011, for psychological treatment after she and her daughter were in a serious Motor Vehicle Accident (MVA) two months prior. DS was driving in the rain on a four lane motorway when hit by a semi-trailer, spinning her vehicle across two parallel traffic lanes. It was then hit by another vehicle before coming to a halt in trees on the median strip. The GP referral indicated DS was suffering from emotional lability, tearfulness, insomnia, nightmares and a general reluctance to drive. Referral objectives were to provide treatment to reduce distress and enable DS to return to driving confidently. DS's CTP insurance company approved her assessment and upon receipt of the assessment report and treatment plan funded eight psychological treatment sessions.

\subsection{Presenting Problems}

During assessment DS reported that since the MVA she had experienced: Intrusive memories of the crash; difficulty falling and staying asleep; nightmares about the crash; difficulties concentrating and pain in her jaw and hands. To overcome her fear of driving she recommenced driving the day after the MVA. Despite this she still felt extremely fearful and reported: 
Experiencing a pounding heart; difficulties breathing; hypervigilance to potential danger; feeling jumpy and easily startled when driving. She subsequently avoided driving on the highway and planned complex routes via local roads to avoid potential contact with trucks. Her intrusive repetitive thoughts included that she and/or her daughter might have died and that she should have better protected her daughter.

\section{CRITICAL REVIEW OF THE SCIENTIFIC LITERATURE: ASSESSMENT AND DIAGNOSIS}

The following literature review explores the research related to assessment and diagnosis of PTSD and its presence in people having experienced a serious MVA.

\subsection{Diagnostic Criteria and Symptomatology of PTSD}

PTSD is a psychiatric disorder first included in the Diagnostic and Statistical Manual of Mental Disorders III (DSM III) almost 30 years ago (Spitzer et al., 2007). Initially conceptualized as a condition primarily manifest in military personnel exposed to combat trauma it is now accepted as a disorder that may develop in adults and children who have direct or indirect exposure to extremely traumatic events such as natural disasters, childhood physical and sexual abuse, vehicular and nonvehicular accidents, terrorist attacks, life threatening situations and illnesses (Bisson and Andrew, 2007).

According to the DSM-IV-TR (APA, 2000) which was the relevant diagnostic manual for the year 2011; to obtain a diagnosis of PTSD an individual must experience or witness an event involving actual or threatened death or serious injury, or threat to the physical integrity of self or others (Criteria A1), in conjunction with intense fear, helplessness or horror (Criteria A2). Differentiation from Acute Stress Disorder (ASD) requires specified core symptoms which are classified into three clusters: Reexperiencing (Criteria B), avoidance and numbing (Criteria C) and hyperarousal (Criteria D) that must all be present for more than one month (Criteria E). The symptoms must cause significant distress and/or impairment across important areas of functioning (e.g., social/occupational) (Criteria F).

The World Health Organization's (WHO) International Classification of Disease 10th Edition (ICD-10; WHO, 1992), an alternative classification typically used in Europe and elsewhere, classifies PTSD (F43.1) as a mental and behavioural disorder associated with reactions to severe stress. The specific ICD-10
Criteria differ from the DSM-IV-TR (APA, 2000) in the areas of subjective distress, the number of avoidance symptoms, the inability to recall some important aspects of the stressor, the number of hyperarousal symptoms, the duration of symptoms, the requirement for functional impairment and numbing of general responsiveness. First (2007) considers the ICD-10 criteria to be less stringent, which may impact on prevalence estimates (given the ICD-10's status as the 'international standard' from an epidemiological perspective).

\subsection{Overlapping Symptoms, Differential Diagnoses and Co-Morbidities}

Owing to symptom overlap, differential diagnoses include adjustment disorders, mood disorders, Obsessive-Compulsive Disorder (OCD) and other anxiety disorders (Benedek and Wynn, 2011), mild traumatic brain injury (especially where loss of consciousness is a factor) (Hoge et al., 2008; Stein and McAllister, 2009), malingering (APA, 2000) and ASD, which is diagnosed in the first 4 weeks and involves a stressor of any severity (ACPMH, 2007).

Approximately $80 \%$ of individuals with PTSD present with a co-morbid psychiatric disorder (Adshead, 2000; Baldwin et al., 2005; Kessler et al., 1995). The Australian National Mental Health and Well Being Study (Creamer et al., 2001) reported that $85 \%$ of men and $80 \%$ of women who met criteria for PTSD also met criteria for another Axis I diagnosis, most commonly major depression ( $51 \%$ of men and $65 \%$ of women), other anxiety disorders (Generalised Anxiety Disorder (GAD) [40\% of men and $22 \%$ of women], social phobia [32\% of men and $13 \%$ of women], panic disorder [15\% of men and $17 \%$ of women]) and alcohol and/or drug abuse/dependence. Blanchard and Hickling's (2004) review of MVA literature found that within the anxiety disorders group, specific fear of travel and/or GAD were most common.

\subsection{Incidence and Prevalence of PTSD}

Studies of rates of exposure to Post-Traumatic Events (PTE) in the general population indicate approximately 50 to $65 \%$ have been exposed to at least one PTE in their lives (Breslau et al., 1998; Creamer et al., 2001; Kessler et al., 1995). The National Co-morbidity Survey (Kessler et al., 1995) indicated that lifetime prevalence of PTSD in American adults was approximately $8 \%$. Considered in the context of the incidence of exposure to PTE's, this indicates that approximately 15 to $25 \%$ of people exposed may also have a diagnosis of PTSD at some time in their life (Breslau, 2001). More specifically, 
Norris (1992) large-scale survey of MVA survivors found the lifetime prevalence of PTSD was $7.4 \%$ with MVA's rated as one of the leading causes in the general population at 2.7 in 100 over a lifetime.

\subsection{Assessment of PTSD}

The International Society of Traumatic Stress Studies (ISTSS) Practice Guidelines (Foa et al., 2009) recommend using multiple measures to conduct a comprehensive assessment for PTSD diagnostic criteria, associated features and co-morbid disorders.

\subsection{Assessment Tools for PTSD}

Assessment tools for PTSD include structured interviews and self-report measures.

\subsection{Structured Interview Schedules}

Structured interview schedules are considered the "gold standard" in diagnosing mental disorders. For PTSD (Weathers et al., 2009) these include the Structured Clinical Interview for DSM-IV (SCID) PTSD module (First et al., 1996); the PTSD Symptom Scale-Interview (PTSD-I; Foa et al., 1993); the Structured Interview for PTSD (SIP; Davidson et al., 1997) and most widely used; the Clinician-Administered PTSD Scale (CAPS; Blake et al., 1990; 1995; 2000). The ISTSS practice guidelines deem interview schedules to have excellent psychometric properties, although the CAPS is the most extensively studied in clinical and research settings (Weathers et al., 2009). It is the only schedule that investigates symptom frequency and intensity using behaviourally specific anchor points (Elhai et al., 2005). The CAPS assesses post-traumatic exposure via the Life Events Checklist (LEC; Blake et al., 1995) which helps determine fulfillment of Criterion A for PTSD diagnosis.

\subsection{Self-Report Measures}

Self-report measures include DSM-Correspondent and other general PTSD focused measures. DSMCorrespondent measures include: The PTSD checklist (PCL; Weathers et al., 1993); the Posttraumatic Stress Diagnostic Scale (PDS; Foa, 1995; Foa et al., 1997) and the Detailed Assessment of Posttraumatic Stress (DAPS; Briere, 2001).

The PDS is a 49-item self-report measure of PTSD symptom severity for a single traumatic event, capturing all DSM-IV criteria A to F for PTSD. It is reported to have strong internal consistency reliability $(\alpha=0.92)$ across the 17 symptom items and good test-retest reliability $(\mathrm{r}=0.83$ for total severity) and inter-rater reliability $(\kappa=0.74)$ for PTSD diagnosis (Foa et al., 1997).
The Impact of Event Scale Revised (IES-R; Weiss and Marmar, 1997) is a PTSD-focused measure commonly used across trauma populations (Newman et al., 1996) and assesses symptoms of intrusion, avoidance, hyperarousal and dissociation. It is considered to be a valid and reliable measure of trauma related symptoms (Sundin and Horowitz, 2002) with good test-retest reliability and internal consistency for each of the subscales (Weiss and Marmar, 1997).

The literature on the PTSD recovery process places emphasis on the role of negative and dysfunctional cognitions in the development and maintenance of PTSD (Beck et al., 2004) and their importance in treatment and recovery. The Posttraumatic Cognitions Inventory (PTCI; Foa et al., 1999) is a 33-item measure, commonly used to identify post-trauma erroneous and negative cognitions that can be targeted in cognitive-behavioural treatment (Foa and Rothbaum, 2001). It produces a total score along with three subscale scores: Negative cognitions about self, negative cognitions about the world and selfblame. The authors report adequate test-retest reliability and convergent and discriminate validity with two other measures of trauma cognitions; the Personal Beliefs and Reactions Scale (PBRS; Resick et al., 1991) and the World Assumptions Scale (WAS; Janoff-Bulman, 1989; 1992); which was confirmed and extended in a replication study with MVA survivors (Beck et al., 2004).

\subsection{Other Assessment Tools Commonly Used}

A Mental Status Examination (MSE), which provides a template for systematic clinical appraisal of a client's emotional and cognitive functioning for diagnoses (Page and Stritzke, 2006), is considered essential to inform case formulation and treatment planning.

The Depression Anxiety Stress Scale (DASS; Lovibond and Lovibond, 1996) measures depression, anxiety and stress from a dimensional perspective and currently exists in two formats. The DASS-21 is a 21item questionnaire scored on a four-point Likert scale and is a valid shortened version of the 42 -item scale (DASS-42). Each scale also provides a total score (0minimum to 42-maximum). The DASS-21 shows adequate test-retest reliability, validity and internal consistency (Antony et al., 1998; Henry and Crawford, 2005; Lovibond and Lovibond, 1996; Ng et al., 2007).

The Travel Anxiety Questionnaire (TAQ; Hickling and Blanchard, 2006) assesses specific driving behavior that might be negatively affected by an MVA. The more items endorsed, the more likely driving has been negatively affected and endorsed items can be specifically targeted in treatment. 
The Subjective Units of Distress Scale (SUDS; Wolpe, 1991) is used for self-assessment of the intensity of distress/disturbance being experienced by an individual, where zero represents no disturbance and 10 or 100 (depending on the scale used) represents the worst distress or disturbance experienced or imagined. The SUDS score can be used as a benchmark to monitor progress of treatment and is typically employed when teaching anxiety management strategies or during exposure sessions.

\section{COMPREHENSIVE ASSESSMENT AND FORMULATION}

\subsection{Client Presentation}

\subsubsection{Mental State Examination (MSE)}

DS attended alone, on time and appeared her stated 54 years of age, presenting as well-groomed in smart casual clothing. She was co-operative with the interview process, maintained good eye contact, smiled appropriately and was open and forthright in her answers. She appeared comfortable and rapport was established quickly. Her speech rate and volume was normal and she answered questions articulately. Her range of affect was appropriate being euthymic on initial presentation, however as she described the MVA her affect changed and was punctuated with anxiety and tearfulness and she described tension in her jaw, hands and shoulders. DS described her mood as generally anxious and she described bouts of irritability. There was no evidence of any perceptual disturbance, formal thought disorder, suicidal ideation or intent. DS was optimistic and forward thinking, alert and oriented to time, place and person. Recent and remote memory appeared unimpaired and she answered questions about her past without difficulty. Insight was good and she exhibited good motivation to engage in treatment.

\subsection{Personal History}

\subsubsection{Patient Detail}

At the time of assessment, DS was a 54 year-old caucasian female, residing with her 56 year-old husband, two daughters aged 17 and 20 years and, for the past six months, her elderly mother who was reportedly suffering from depression. Ten years prior DS's father died of a heart attack. Her youngest daughter, MS, was attending grade 12 at a local high school and her eldest daughter, KS, was attending TAFE.

\subsection{History of Presenting Problems and Precipitating Factors}

DS was referred for psychological treatment by her GP post the MVA owing to concerns about emotional lability, tearfulness, insomnia and nightmares. She described suffering menopausal-related depressive symptoms five years ago, which was treated successfully with antidepressants. Prior to the MVA DS experienced minor life stressors associated with her elderly mother's recent cohabitation. At the time of the MVA, as her youngest daughter had almost finished her schooling, she was considering returning to the workforce from which she had been absent since the birth of her first child.

DS presented for initial assessment eight weeks post MVA. She reported heightened general anxiety, manifest as agitation, difficulty relaxing, trembling and shaking, dryness of the mouth; and increased worry and anxiety when travelling by car. Car travel reportedly precipitated panic-like symptoms (increased heart rate, sweating, difficulty breathing) when travelling on the highway or when a truck passed her and exacerbation of muscle tension leading to pain in her jaw, hands and back.

Other symptoms included sleep disturbance (difficulty getting to sleep, staying asleep and nightmares about the MVA); decreased ability to concentrate; preoccupation with thoughts and memories associated with the MVA including intrusive memories of the MVA and unpleasant thoughts that she and her daughter may have died; flashback experiences of the spinning vehicle and seeing her daughter's pallid terrified face.

Neither DS nor her daughter MS was seriously injured requiring hospitalization; MS suffered a whiplash neck injury requiring physiotherapy and a neck brace. DS described guilt associated with the belief that she should have better protected her daughter. Following the crash she stayed calm until the ambulance arrived despite being trapped in the motor vehicle and MS being "hysterical". After MS was treated DS described that everything "felt surreal and like it was happening in slow motion" and she "fell apart and became hysterical" herself when she realised they could have died.

\subsection{Developmental and Family History}

DS, the eldest of two daughters, was born six weeks premature and experienced feeding problems as a baby. She was raised in rural Australia and married at age 24. She was an overweight child and experienced considerable tormenting through primary school. DS described a generally happy family life until she became the family primary carer at age 15 when her mother was 
hospitalised for "a nervous breakdown". She completed secondary school with average marks and began work in the local newsagents. She met her husband and moved to the Brisbane after the birth of her first daughter KS. The marriage was described as "happy" and her daughters had been easy to raise with only typical teenage limits-testing. After her father died 10 years ago her mother relocated to be closer to the family and finally moved in with them approximately six months ago having become significantly depressed. Socially, DS reported positive and long lasting relationships within the social network at her daughters' school and with close childhood friends.

\subsection{Predisposing, Risk and Perpetuating Factors}

The literature indicates several risk factors that increase the likelihood of developing PTSD. These can be summarised into four main groups: (1) Variables that are specific to the individual (age, gender, previous psychological dysfunction, genetic predisposition, family dysfunction previous traumatic experiences); (2) characteristics of the stressor (extent of exposure, presence of life threat, witnessing of death, unpredictability and uncontrollability, loss of loved one, physical injury, whether it was an event of nature or human caused); (3) the individual's emotional response to the stressor (their perception of threat, cognitive predispositions, degree of perceived or actual responsibility felt for the event, intensity of negative emotional responses immediately post event, experience of dissociative reactions at the time of stressor); and (4) the responses towards the survivor from those around them including the degree of emotional, physical and material support they receive (Briere, 2004; Vogt et al., 2007).

In MVA survivors a number of other specific risk factors for the development of PTSD have emerged from the literature: (1) Being deemed to not be responsible for their accident (Chossegros et al., 2011; Hickling et al., 2005); (2) having more serious or severe injuries (Blanchard and Hickling, 2004; Chossegros et al., 2011; Mayou, 2002); (3) the presence of ongoing litigation (Beck and Coffey, 2007; Blanchard and Hickling, 2004; Hickling et al., 2005; Mayou, 2002) and (4) persistence of pain six months post-accident (Chossegros et al., 2011; Mayou, 2002; Sharp and Harvey, 2001).

DS reported no history of PTSD or PTE prior to the MVA. She reported a menopausal related depressive episode in 2006, treated successfully with medication. Family psychiatric history includes; the history of her mother's nervous breakdown and no other reported episodes of depression or other psychiatric history within the family. Other risk factors for DS include: Gender, with females more likely to develop PTSD; that the event was unpredictable and uncontrollable and involved both real and perceived life threat; intense negative emotional responses and a dissociative reaction post the event.

Possible perpetuating factors include ongoing injury rehabilitation for MS; avoidance of driving on the highway in order to avoid the distress associated with traumatic reminders which according to learning theory maintains PTSD symptoms (Cahill and Foa, 2007); DS's mother's depression; the insurance claim and possible legal proceedings and problematic core beliefs as identified on the PTCI.

\subsection{Strengths and Protective Factors}

DS sought treatment promptly and demonstrated strong motivation and commitment to it. This was supported by her positive experiences of previous psychological treatment and cognizance of when she had coped well with difficulties in the past. She was open and intelligent, displaying good insight into her travel anxiety by continuing to drive despite her fear. She had experienced a positive response from bystanders, medical personnel and the insurance company post MVA and felt hopeful about returning to her pre-MVA functioning amidst good family relationships and positive support from family and friends. DS had not witnessed any death or loss of a loved one in the MVA nor had she suffered any serious physical injuries or debilitating or severe chronic pain.

\subsection{Assessment Results}

DS's Life Events Checklist (LEC) results indicated endorsement of the recent MVA as a single traumatic incident and no others. The description of the event fulfilled DSM IV-TR Criterion A for PTSD, A1 and A2.

The CAPS was used for a comprehensive assessment for PTSD based on the research evidence that is the most extensively studied structured interview schedule for PTSD (Weathers et al., 2009). Using the more stringent recommended scoring rules of F1/I2 (Frequency 1, Intensity 2) and TSEV65 (Total Severity score of 65) (Blake et al., 2000) DS's responses fulfilled the DSM IV-TR criteria for Acute PTSD (APA, 2000). She scored a symptom severity total of 85 and fulfilled the F1/I2 rule for five of five re-experiencing (Criterion B), five of seven avoidance and numbing (Criterion $\mathrm{C}$ ) and five of five hyperarousal (Criterion D) symptoms. The duration of the disturbance was two months (Criterion E) and involved significant distress and impairment in social and occupational functioning, satisfying Criterion F. As the duration of symptoms was less than three months her 
PTSD was specified as Acute. On the Associated features questions (26 to 30 ) DS endorsed a positive on question 26 "guilt over acts of commission or omission" with a score of two on frequency (some of the time) and a two on intensity (moderate, guilt feelings definitely present, some distress but still manageable). Further questioning revealed that DS was experiencing guilt associated with the belief that she "should have protected her daughter better". DS had experienced some derealisation (question 29) immediately post the MVA but had no recurrence in the last month.

The self-report questionnaires DASS21, PDS, IES-R, PTCI and Travel Anxiety Questionnaire were completed. Results of the PDS and the IES-R were used to establish convergent validity for the CAPS, based on research (Foa et al., 1997; Weiss and Marmar, 1997) suggesting that these self-report instruments are valid and reliable measures of symptoms associated with PTSD. On the PDS, 16 of a possible 17 symptoms were endorsed with ratings of "severe" on both symptom severity and level of impairment in functioning. A total score of 62 on the IES-R was significantly higher than the recommended cut-off score of 33 (Creamer et al., 2003) indicating a high amount of emotional distress and likely diagnosis of PTSD. The PDS and IES-R results concurred with the CAPS supporting the DSM IV-TR diagnosis of Acute PTSD (APA, 2000).

Owing to the reported history of depression further investigation was completed and confirmed no current significant symptoms of depression. On the DASS-21 DS scored in the "Normal" range for depression (8) at the 59th percentile, the "Severe" range for anxiety (16) at the 99th percentile and in the "Moderate" range for stress (22) at the 93rd percentile. DS was not taking any psychotropic medications or illicit substances. With an occasional glass of wine when dining out her alcohol consumption was not considered excessive.

The PTCI was used to identify specific trauma beliefs for use in Cognitive Behavior Therapy (CBT) and the TAQ provided specific behavioural markers for goals in exposure treatment. DS's total PTCI score of 97 was more representative of individuals experiencing "trauma with PTSD" than for those experiencing "no trauma" or "trauma but no PTSD". Her scores on the "negative cognitions about self" and "negative cognitions about the world" subscales were representative of individuals who have experienced "trauma with PTSD". Her score on the third subscale, "self blame", was representative of individuals who have experienced "no Trauma" and "trauma but no PTSD" and reflected that DS did not blame herself for the MVA or the difficulties since.
DS's responses on the TAQ indicated that she was experiencing severe anxiety associated with driving situations that were similar to the traumatic event (driving on the highway, driving in heavy traffic, driving with trucks and in the location of the MVA) and that her avoidance of these situations was "all the time".

DS's responses in the assessment interview and across self-report questionnaires revealed no internal inconsistencies nor did she appear to be exaggerating her symptoms. At the time of treatment DS had not instigated any legal action. She appeared highly motivated to return to premorbid functioning. Overall, these results support the assessment as being valid and reliable representation of her current condition with malingering considered highly unlikely.

\subsection{Multi-Axial Diagnosis}

At interview/baseline DS met criteria for the following:

- Axis I 309.81 Posttraumatic Stress Disorder Acute

- Axis II

- Axis III

- Axis IV the family

- Axis V

\section{V71.09 No diagnosis}

None

Adjustment to mother moving in with

$\mathrm{GAF}=56$ (current)

\subsection{Differential Diagnoses}

- $\quad 309.24$ Adjustment Disorder with Anxious Mood

- $\quad 308.3$ Acute Stress Disorder

- 300.29 Specific Phobia Situational Type

\section{CRITICAL REVIEW OF THE SCIENTIFIC LITERATURE FOR TREATMENT OF PTSD}

World authorities generally agree on the treatment guidelines for PTSD with only minor differences reported. The Australian Guidelines for Treatment of Adults with Acute Stress Disorder and PTSD (ACPMH, 2007) and British Guidelines (NICE, 2005) specifically indicate the first line of treatment is in vivo exposure with the addition of Trauma-Focused Cognitive Behavioural Therapy (TF-CBT) or Eye Movement Desensitization and Reprocessing (EMDR). Although currently not included as a recommended treatment in the world authority guidelines, the last few years have seen an accumulation of evidence for the effectiveness of using the Emotional Freedom Techniques (EFT) in treating people presenting with PTSD symptoms 
(Church, 2013; Church and Feinstein, 2013; Feinstein, 2012; 2010). In a recent study by Karatzias et al. (2011) comparing the use of EFT and EMD-R to treat PTSD symptoms, both were found to produce effective clinical change in an equal amount of sessions. The (2007) and NICE (2005) recommend psychopharmacological treatment should not be used as a preferred routine first line therapy, but be considered adjunctive to trauma-focused psychological therapy when a person has not gained benefit from psychological therapy alone.

\subsection{Psychosocial Treatments}

A significant amount of literature exists on the psychological treatment of PTSD covering a broad range of interventions (APS, 2010; Bisson and Andrews, 2009; Bisson et al., 2007; Cukor et al., 2010; Najavits, 2002), however comparison of research studies on the effectiveness of treatments is complicated by high attrition rates (Schottenbauer et al., 2008); treatment combination versus single treatment modalities and heterogeneous, population groups and trauma types (Schottenbauer et al., 2008). Notwithstanding, metaanalyses and systematic reviews conducted in the last 10 years (ACPMH, 2007; Bisson and Andrew, 2009; Bisson et al., 2007; Bradley et al., 2005; Cloitre, 2009; APS, 2010; Ponniah and Hollon, 2009; VA/DoD, 2010) indicated that sound evidence exists for the effectiveness of trauma-focused psychological treatments for chronic PTSD, but not for treatments that did not focus on the patient's traumatic memories.

A number of systematic reviews and meta analyses (Roberts et al., 2009a; 2009b; 2010) concluded that for those people showing acute traumatic stress symptoms post-incident, TF-CBT was effective when compared to both wait list and supportive counseling groups. Rothbaum et al. (2012) investigated the effect of a modified individual prolonged exposure treatment versus assessment on a mixed trauma sample within $12 \mathrm{~h}$ post incident. Results indicated that the intervention was effective at reducing posttraumatic stress reactions and depression.

\subsection{Trauma-Focused Cognitive Behavior Therapy (TF-CBT)}

TF-CBT for PTSD includes diverse techniques broadly encompassing: Coping skills focused interventions (stress inoculation, fear management and relaxation training) for anxiety and reconditioning anxiety responses; exposure therapy for response reduction by re-experiencing the trauma event in controlled conditions with corrective information incorporated into existing fear structures (Iverson et al., 2011); Cognitive Therapy (CT) including Cognitive Processing Therapy (CPT) with relaxation techniques and narration of the traumatic event orally or in writing (VA/DoD, 2010) to modify maladaptive interpretations or appraisals of events that lead to negative emotional states; and in some complex cases, such as adults exposed to childhood abuse, the addition of skills training such as affect regulation and interpersonal effectiveness (Iverson et al., 2011).

CBT is normally a short term treatment of approximately eight to 12 sessions of 60 to $90 \mathrm{~min}$ duration once to twice weekly. Some patients may need fewer sessions; others with more complex conditions and comorbidities may need longer (Cahill et al., 2009).

Exposure therapy (EX) is possibly the most investigated CBT component and involves exposing the client to anxiety provoking stimuli associated with the trauma. It is frequently used with other CBT techniques such as CT. EX can be imaginal, in vivo or a writing task. Most commonly imaginal exposure is used for traumatic memories and in vivo exposure for feared and avoided (but low risk) stimuli such as people, places, situations or activities (Cahill et al., 2009). At the time of publishing in 2009, the ISTSS guidelines cited 24 Randomized Controlled Treatment (RCT) studies supporting EX use across trauma populations.

Other empirically supported CBT interventions include variations on Stress Inoculation Therapy and Cognitive Therapy (CT) (Cahill et al., 2009) including Cognitive Processing Therapy (CPT), Some 13 RCT's have explored their use with positive outcomes for diverse trauma populations including female rape and interpersonal violence victims (Foa et al., 1999; 1991; Resick et al., 2002; Resick et al., 2008); childhood sexual abuse (Chard, 2005); male and/or female veterans (Chemtob et al., 1997; Monson et al., 2006); MVA victims (Ehlers et al., 2003); terrorist bomb attack survivors (Duffy et al., 2007) and mixed gender/trauma population (Ehlers et al., 2003; Marks et al., 1998; Tarrier et al., 1999).

\subsection{Eye Movement Desensitization and Reprocessing (EMDR)}

EMDR, a technique developed by Francine Shapiro in 1987 has been more controversial in its acceptance as effective for the treatment of PTSD (Berg et al., 2008). It involves attending to bilateral stimulation such as eye 
movements, hand tapping or auditory tones in conjunction with exposure therapy through recall of trauma related memories, emotions, body sensations and thoughts (Ponniah and Hollon, 2009). A review of seven meta-analyses by Spates et al. (2009) concluded that it was comparable to exposure based therapy in terms of effectivness, although one meta-analysis conducted by Davidson and Parker (2001) concluded that the data did not support any incremental benefit of the eye movements or any other bilateral stimulation. Despite this conclusion EMDR has been rated by various authorities as having Agency for Healthcare Research and Quality (AHCPR) Level A evidence, considered the highest, for effectiveness in treating adult PTSD (APS, 2010; Spates et al., 2009) and is recommended by the ACPMH (2007) and NICE (2005) as a first line treatment.

\subsection{Emotional Freedom Techniques (EFT)}

EFT has been classed as an energy psychology therapy and was developed by Craig (2008) as an abbreviated method derived from the complex diagnostic and treatment protocols of Thought Field Therapy (Callahan and Trubo, 2002). It has been studied and found to be efficacious as a clinical intervention for a variety of psychological conditions including PTSD (Church et al., 2013; 2012; Sakai et al., 2010); anxiety and phobia's (Jones et al., 2011; Salas et al., 2011; Sezgin and Özcan, 2009); depression (Church et al., 2012; Stapleton et al., 2013); pain (Brattberg, 2008) and weight loss and cravings (Stapleton et al., 2011; 2012). EFT involves traditional exposure therapy and cognitive restructuring with the addition of somatic stimulation of certain acupressure points (Church, 2013) that are hypothesized to send signals that are deactivating to the amygdala (Fang et al., 2009; Feinstein, 2010). A clinical report provided by Burke (2010) examined the use of EFT for three people presenting with stress related symptoms post an MVA. Each person was treated with a single session of EFT resulting in rapid relief of PTSD symptoms in all three cases.

\subsection{Combined Versus Single Modality Treatment}

Direct comparisons between the different CBT treatments deemed effective, including EMDR, have generally found comparable outcomes as have those comparing combined treatment programs with individual modality treatments (Spates et al., 2009).

\subsection{Group Therapy}

Research on the effectiveness of group therapy for the treatment of PTSD is suggestive that it is better than waitlist or no treatment (Shea et al., 2009) and world authorities (ACPMH, 2007; NICE, 2005; ISTSS, 2009) recommend its use as adjunctive to individual treatment, but not as a standalone treatment.

\subsection{Pharmacotherapy}

A rationale for the use of pharmacotherapy has arisen from significant evidence that a number of alterations in key neurobiological mechanisms occur in association with PTSD (Bonne et al., 2004; Charney, 2004; Neumeister et al., 2007; Southwick et al., 2007; Yehuda and McFarlane, 1995) in conjunction with the considerable overlap of symptoms with other anxiety disorders and depression and the frequent co-morbidity with other psychiatric conditions that respond to medication (Friedman et al., 2009).

The use of medication as a first line treatment of adult PTSD is contentious, as evidenced by the differing professional practice guidelines worldwide $(\mathrm{ACPMH}$, 2007; APA, 2000; ISTSS, 2009; NICE, 2005; VA/DoD, 2010). Indeed a recent review (Hetrick et al., 2010) found no difference between groups using combined pharmacotherapy (SSRI) and CBT and those using either psychological or pharmacological treatment alone.

Notwithstanding, SSRI's are the recommended firstline pharmacological treatment (ACPMH, 2007; APA, 2000; Bandelow et al., 2008; ISTSS, 2009; NICE, 2005; VA/DoD, 2010) based on consideration that SSRI's reduce PTSD symptoms, are effective against co-morbid disorders and associated symptoms and have greater safety and fewer side effects than other antidepressants (e.g., Tricyclics and MAOI's) (APA, 2000; Bandelow et al., 2008; ISTSS, 2009). However, overall response rates are considered low as less than $50 \%$ of patients improve on SSRI's (Foa et al., 2002) and barely 30\% achieve full remission (Berger et al., 2009). Results for the newer alpha-2 antagonist Mirtazapine (Bahk et al., 2002; Davidson and Parker, 2001; Kim et al., 2005) and SNRI Venlafaxine (Davidson et al., 2006a; 2006b; Stahl et al., 2005) have been promising and trials are ongoing at this time.

A number of small RCT's on the use of atypical antipsychotics indicate that they may be useful as an adjunctive treatment for patients with PTSD who exhibit symptoms of psychosis, paranoia, physical aggression or for refractory patients who have failed to respond to SSRI'S (Friedman, 2011; Friedman and Davidson, 2010; Friedman et al., 2009). Benzodiazepines, in contrast, are contraindicated for PTSD treatment because of their sedating effects, without reducing typical PTSD symptoms (Friedman et al., 2009; Stein et al., 2009; Ipser and Stein, 2012). 


\section{DESCRIPTION OF TREATMENT CONDUCTED AND CASE OUTCOME}

\subsection{Applying the Evidence}

When applying the research evidence to clinical case work Rubin (2007) emphasizes the importance of individually tailoring a treatment program to consider the client's goals, values and preferences along with their personal circumstances and the experience of the practitioner.

\subsection{Description of Treatment Conducted}

The choice of psychological intervention including TF-CBT, EX, (both imaginary and in vivo) and EFT, in the current case of DS was based on all of the aforementioned research and the fact that DS had used EFT in the past successfully for food craving management and was comfortable with the technique. The specific components of the treatment program included psychoeducation about PTSD and the rationale for EX treatment, CBT and EFT; relaxation training including Progressive Muscle Relaxation (PMR) and controlled breathing; cognitive restructuring and EFT for maladaptive and dysfunctional beliefs resultant from the incident; imaginary prolonged exposure through verbal and written narrative with EFT treatment for sections of the narrative that produced strong emotional responses or distress; in vivo exposure for avoided driving stimuli and homework tasks. The research into MVA-related PTSD was also utilised for treatment of travel anxiety. Before exposure treatment was initiated DS's medical practitioner was consulted to exclude health-based contraindications. The CTP insurance company approved eight treatment sessions consequential to the assessment report.

\subsection{Treatment Goals}

The psychologist and client collaboratively developed treatment goals, which included:

- Decrease emotional distress and intrusive memories, thoughts and ruminations

- Decrease hyperarousal symptoms in general and on exposure to traumatic reminders in particular, to be indicated by attenuation of anxious physiology and cognitive state when confronted with reminded of the event

- Improve sleep and relaxation skills

- Decrease avoidance of driving on highways, night driving, driving in the rain and/or near trucks, indicated by calm driving on highways under these same conditions

- Decrease negative cognitions about self and the world

- Improve overall functioning, sense of wellbeing and safety indicated by reported improvements in concentration and sleep, decrease in anxious physiology, decrease in muscle tension and change in trauma-influenced cognitions

\subsection{Length of Treatment}

Treatment occurred across six sessions with the first five occurring once weekly and the last session three weeks later. Session length was either 60 or $90 \mathrm{~min}$ duration with details of sessions included below. Each session included a session rating scale and SUDS rating for distress during the preceding week.

\subsection{Treatment Session $1 \quad(90 \quad \mathrm{~min})$ : Psychoeducation and Feedback}

After the assessment was complete and outcomes discussed, this session focused on: Development of the clinical formulation; psychoeducation about common reactions in PTSD using specific examples from DS's experience for practical illustration; treatment rationales for prolonged imaginal and in vivo exposure in conjunction with EFT to treat cognitive and behavioural avoidance; controlled breathing training, progressive muscle relaxation and EFT to manage symptoms of hyperarousal and sleep disturbance; cognitive therapy and EFT for trauma based beliefs and thoughts and a summary of the goals and format of treatment sessions.

A controlled breathing and PMR skills training session was included and recorded as auditory files on DS's iPhone for playback and use in the homework practice set. EFT was used in session on physiological symptoms of hyperarousal including constricted breathing, muscle tension and increased heart rate.

Homework included: A handout on common reactions to trauma to read and share with family members and practice in the use of EFT, PMR and controlled breathing exercises twice a day to be recorded on a provided record form.

\subsection{Treatment Session 2 (60 $\mathrm{min})$ : Cognitive Therapy and EFT for Traumatic Thoughts and Beliefs}

Homework tasks were reviewed and a SUDS rating of 60 (100 being the highest) was reported by DS for the level of distress during the week. Session focus was on recognizing the effect of traumatic experiences on beliefs 
and thoughts. An automatic-thought monitoring form (situations, emotions, automatic thoughts) was utilized to demonstrate the concepts using examples of unhelpful thinking patterns from DS's PTCI responses.

DS reported the thoughts that were having the most significant effect were "that she could have died" and that she "should have protected her daughter". EFT was conducted focusing on these beliefs and the fear associated with initial distress rated on the SUDS at 80 or 90 and after 10 to $15 \mathrm{~min}$ at a zero. Homework was to write the story of the MVA with as much detail as she could including her thoughts and feelings, monitor and record unhelpful thinking patterns (see Appendix B for a copy of form provided) and to continue EFT, PMR and controlled breathing practice for managing hyperarousal symptoms.

\subsection{Treatment Session 3 (90 min): Imaginal Prolonged Exposure with EFT and the Development of a Travel Fear Hierarchy}

Homework tasks were reviewed and a SUDS rating for the week of 35 was reported. DS reported that during the week the travel needs had necessitated her driving on busier roads.

Exposure treatment commenced with DS telling the story of the event in first person narrative with as much detail as possible. When DS reported finding an emotional 'hot spot', detail was requested and an EFT setup statement and treatment rounds were implemented. Once her distress was at a SUDS of 10 or less the story continued with a repetition of EFT treatment for each emotional 'hot spot' that occurred. Recorded SUDS ratings were: 80 at pre, 95 at peak and 0 at post after three repetitions of the story in the 40 min session.

A collaborative travel fear hierarchy was developed as listed in Table 1. All travel situations from one to six were being actively avoided, with situation seven minimized by DS. The next session was planned for two days hence to start in vivo exposure treatment on travel situations five and six with the treating psychologist to accompany DS.

Homework tasks were: To continue to read the story of the event out loud during the week daily; continue monitoring and recording unhelpful thoughts and daily EFT, PMR and controlled breathing exercises for hyperarousal and pain symptoms.

\subsection{Treatment Session 4: $(60 \mathrm{~min})$ in Vivo Exposure to Travel Situation 5 and 6}

SUDS pre-session was rated at 70 , peak at 75 and post at 50. A coping statement was installed with EFT and used while driving, when trucks passed. This coping statement was recorded on DS's iPhone for homework use. Homework comprised: Continued exposure by daily travel on two lane one way main roads for a minimum of $45 \mathrm{~min}$; to continue challenging unhelpful thinking and daily EFT, PMR and controlled breathing exercises. Planned next session was for in vivo exposure to travel situations 3 and 4 and if time and anxiety levels permitted; in vivo exposure of travel situation 1 as listed in Table $\mathbf{1 .}$

\subsection{Treatment Session 5: $(90 \mathrm{~min})$ in Vivo Exposure to Travel Situation 3, 4 and 1}

Homework reviewed and most recent post-SUDS for driving on the local two lane main roads was reported at 0 . DS reported the coping statement had been helpful and she felt "aware" rather than anxious driving on local single and two lane roads. Prolonged in vivo exposure session on the local four lane, one way, high speed $(110 \mathrm{kph})$ highway for a total of 35 min with pre SUDs reported at 95, peak at 100 when sandwiched between two semi-trailers and post at SUDS 30. A brief break of $10 \mathrm{~min}$ was taken and EFT conducted on any concerning thoughts she had about doing in vivo exposure on travel situations 1 .

Prolonged in vivo exposure to travel situation 1 began with a SUDS of 65 and after $35 \mathrm{~min}$ had diminished to a SUDS of 20. Homework set was to continue daily travel on whatever roads were necessary and to not avoid highway travel nor the accident site. The next session plan was for a review in three weeks time.

\subsection{Treatment Session 6: $(90 \mathrm{~min})$ Review of Goals and Progress and Relapse Prevention Planning (3 Weeks Later)}

DS was given the PTCI, PDS, IES-R and DASS21 to complete. A review of goals and progress with DS indicated that she had made significant progress with travel anxiety reporting that she now felt she was "aware" rather than anxious while driving (Table 2 for details). She had spontaneously driven past the MVA site the previous week and stated she felt no anxiety. Her lower back, neck and hand tension were reduced from a SUDS (zero to ten scale) of eight, to one and jaw tension from nine to two. She reported that during the last week she had not been troubled by any intrusive memories or thoughts and was feeling almost "back to my old self" and the CAPS was re-completed.

DS felt it appropriate to finish sessions with session six and was confident to continue to use the strategies taught and indicated she would re-contact if needed. 
Table 1. Collaborative travel fear hierarchy

\begin{tabular}{|c|c|c|}
\hline Travel situation & & Initial SUDS \\
\hline \multicolumn{3}{|c|}{ Driving on the 3 or 4 lane one way highway sandwiched between two semi-trailers in both adjacent lanes } \\
\hline Driving past the MVA site & & 100 \\
\hline Driving on the 3 or 4 lane one way highway +1 semi-trailer passing & & 90 \\
\hline Driving on the 3 or 4 lane one way highway + no semi -trailers passing & & 85 \\
\hline Driving on 2 lane one way main road +1 semi-trailer passing & & 75 \\
\hline Driving on 2 lane one way main roads + no semi-trailer passing & & 65 \\
\hline Driving on single lane roads & & 55 \\
\hline Travel situation & SUDS pre treatment & SUDS at session 6 \\
\hline \multicolumn{3}{|l|}{$\begin{array}{l}\text { Driving on the } 3 \text { or } 4 \text { lane one way highway sandwiched between } \\
\text { two semi trailers in both adjacent lanes }\end{array}$} \\
\hline Driving past the MVA site & 100 & 10 \\
\hline Driving on the 3 or 4 lane one way highway +1 semi trailer passing & 90 & 5 \\
\hline Driving on the 3 or 4 lane one way highway + no semi trailers passing & 85 & 0 \\
\hline Driving on 2 lane one way main road +1 semi trailer passing & 75 & 0 \\
\hline Driving on 2 lane one way main roads + no semi trailer passing & 65 & 0 \\
\hline Driving on single lane roads & 55 & 0 \\
\hline
\end{tabular}

Relapse prevention was discussed and included: A plan for continued use of strategies to address some low frequency and intensity symptoms revealed in the CAPS interview; possibility of re-experiencing of some symptoms even after "recovery", such as the anniversary date of the MVA; discussion of early warning signs that could identify slips which could trigger use of relapse prevention strategies (such as rereading resources; stress inoculation strategies; automatic thought and cognitive restructuring worksheets; use of EFT on distressing thoughts, feelings and pain; developing and implementing new hierarchies and being aware of any possible behavioural avoidance).

\section{RESULTS}

Responses on the CAPS, PDS, IES-R, PTCI and DASS21 are depicted in Fig. 1-5 reflected changes in scores from pre (assessment) to post treatment.

Using the recommended value of a 15 point change on CAPS total severity as a marker of clinically significant improvement (Blake et al., 2000), DS's change from 85 (pre) to 13 (post) is clinically significant (Fig. 1 below). Further she no longer qualified for a diagnosis of PTSD. Her global severity rating on the CAPS had improved from a two (moderate) to a one (mild) and her global improvement score of one indicated she had made considerable improvement but was not yet completely asymptomatic.
The results of the CAPS were supported by similar reductions of scores below the threshold for clinical significance on the PDS (Fig. 2) and the IES-R (Fig. 3).

Figure 4 below illustrates that DS's responses on the PTCI had also changed with her total score posttreatment being more reflective of a person who had suffered a trauma but did not meet criteria for PTSD.

DASS21 results as depicted in Fig. 5 indicate that DS's scores on all subscales of the DASS had decreased. Statistical analyses for reliable and clinical change on scores pre- and post-treatment (see Appendices C, D and E for calculations) indicated that DS's score on the Anxiety and Stress subscale both reflected reliable and clinical change from the clinical to normal population at a confidence level of $99 \%$ (2.58 standard deviations). Her pre-treatment score on the Depression subscale was in the normal range and declined further post-treatment, however it did not reach significance owing to a likely floor effect.

At post-treatment DS no longer qualified for a diagnosis of PTSD although she still reported some symptoms on Criterion B (re-experiencing symptoms) and Criterion D (hyperarousal symptoms) within the previous month however all were of low frequency (score of 1) and intensity (score of 1). In a follow-up phone call one month post-session six, approximately six months post-incident, DS reported that she was asymptomatic and the low frequency and intensity reexperiencing and hyperarousal symptoms previously reported in session six had ceased. 
Terri Sheldon / Current Research in Psychology 5 (1): 40-63, 2014

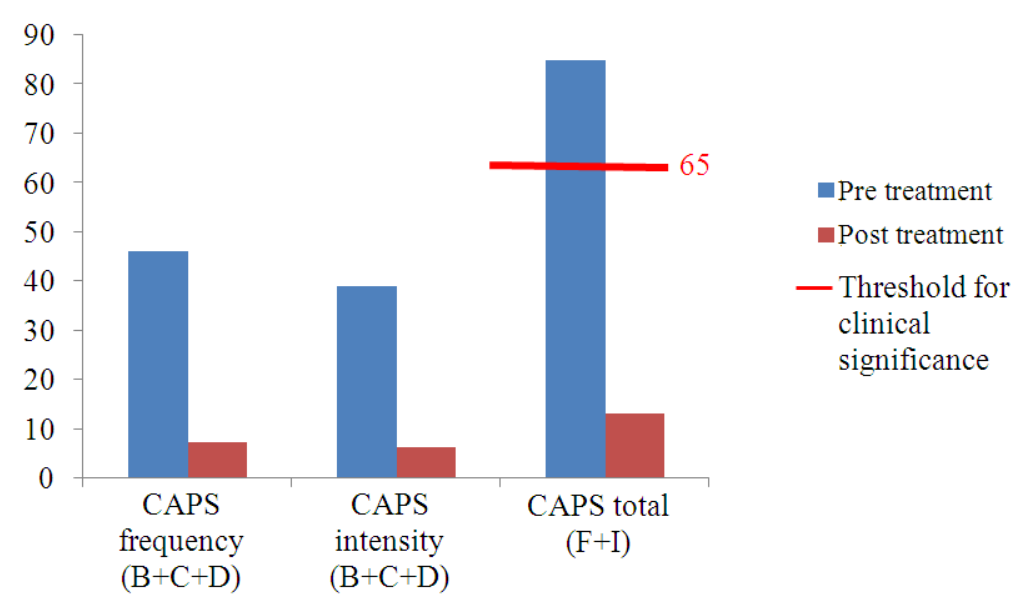

Fig. 1. Results of the CAPS pre (assessment) and post treatment

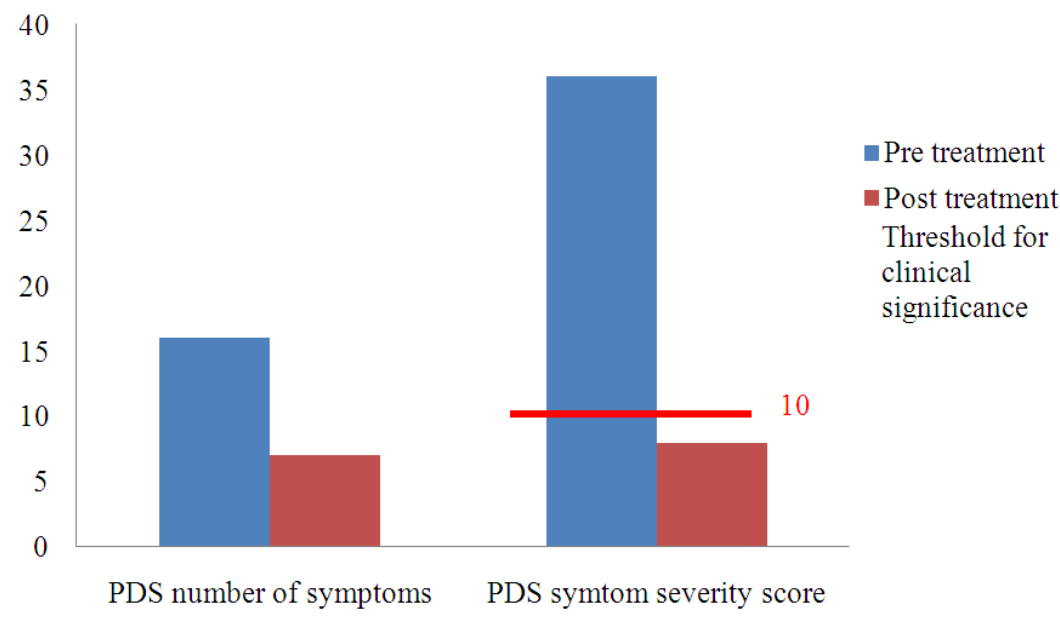

Fig. 2. Results of the PDS pre (assessment) to post treatment

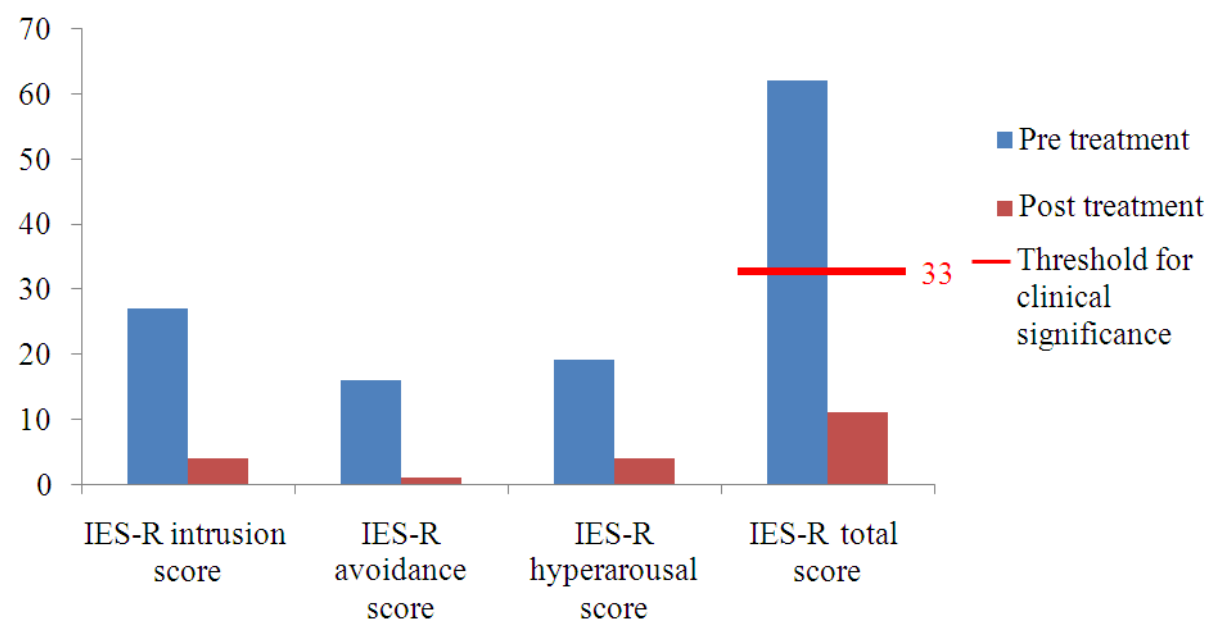

Fig. 3. Results of the IES-R pre (assessment) and post treatment 


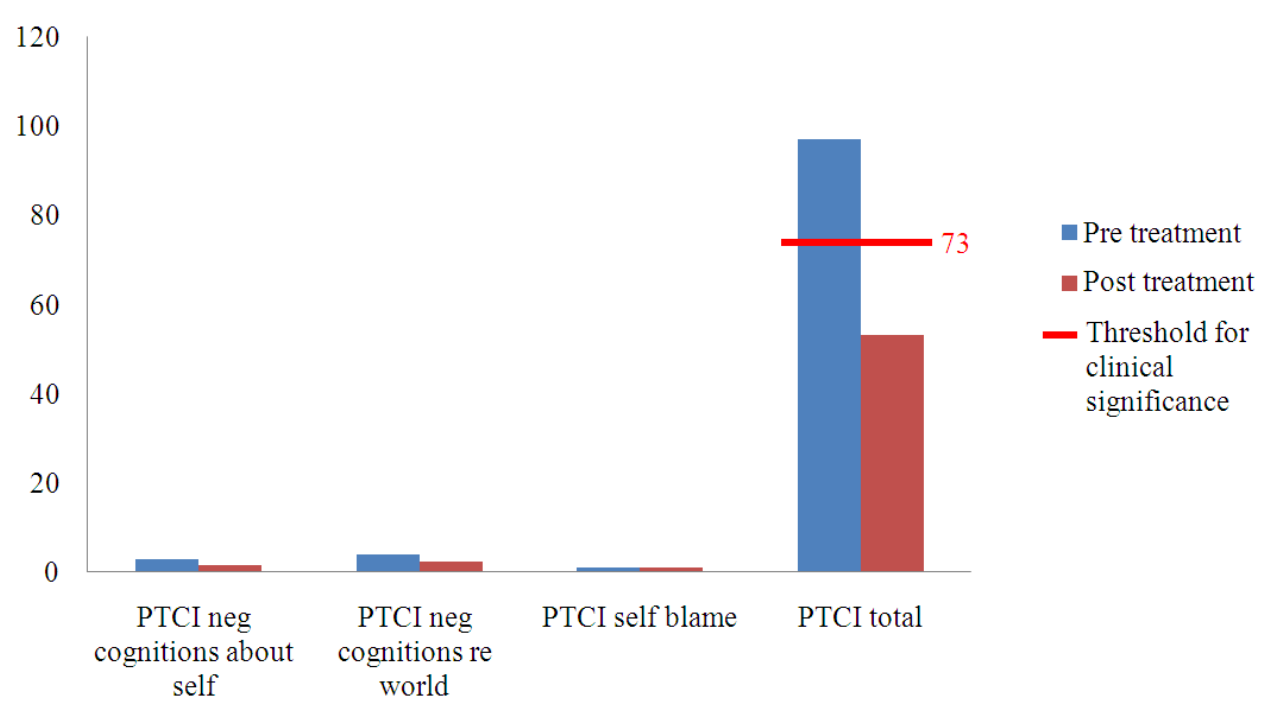

Fig. 4. Results of the PTCI pre (assessment) and post treatment

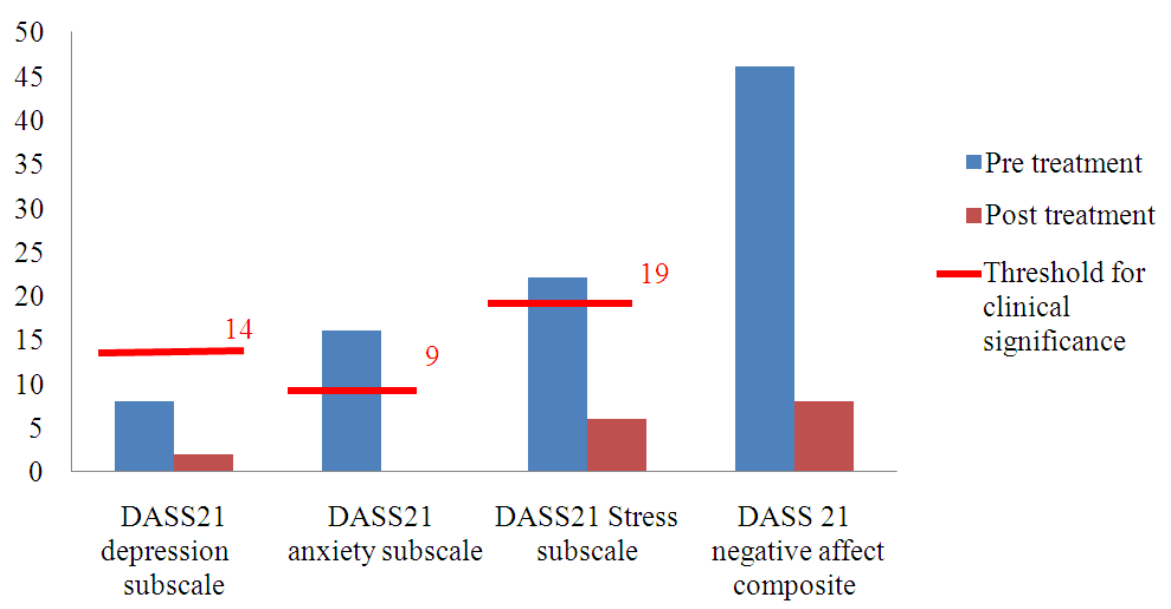

Fig. 5. Results of the DASS21 pre (assessment) and post treatment

\section{EVALUATION AND CRITIQUE}

\subsection{Positive Outcomes}

DS engaged well in treatment and exhibited significant motivation completing all homework tasks. Of her own volition and in her eagerness, she extended her exposure homework despite the considerable reported fear. This could have been potentially problematic if difficulties had occurred for which she was unprepared; however, fortunately this did not occur. Rapport and therapeutic alliance was easily established and with the aid of the assessment findings, diagnosis, collaborative goals and the treatment plan were readily accepted by DS.
Psychoeducation about PTSD and the rationales for all treatment methods used facilitated DS's understanding, commitment and engagement. Collaboratively conceptualizing DS's concerns along with her strengths and positive coping mechanisms and normalizing her reactions to the extreme stressor was integral in helping DS comprehend that her problems were understandable, manageable and treatable. DS's commitment to facing her fears was exhibited pre-treatment by her preparedness to continue driving immediately post the MVA despite feeling very anxious. DS reported that having the treatment therapist present in the car for prolonged exposure driving sessions increased her motivation and confidence in the treatment process. This also allowed for more control over the treatment process and 
immediate access to DS's fear responses which could be treated accordingly.

EFT and stress inoculation training was beneficially used for DS in the early stages of treatment to help her manage hyperarousal, pain and muscle tension symptoms with good results, allowing her to learn skills that she could immediately apply. The use of technology (iPhone) to record the controlled breathing and PMR exercises and to replay a 'coping statement' was particularly beneficial and enabled her to have a portable tool to use which increased her confidence in applying the techniques.

DS's prognosis for recovery was positive due to the fact that: The traumatic event was a single incident; she had no history of any prior significant trauma or Axis II diagnoses; she had no co-morbid depression or substance abuse difficulties; she did not experience the loss of a loved one in the accident nor was she or anyone else seriously or critically injured in the MVA.

In accord with the Australian (ACPMH, 2007) and the British (NICE, 2005) guidelines pharmacological treatment was not used as adjunctive or a first line treatment for DS although it was considered during the assessment process and was reconsidered throughout treatment and ruled out based on DS's responses and progress.

The prediction that CBT, EFT and prolonged exposure would be the appropriate treatment for DS's presentation was accurate and that she did in fact benefit was reflected in results on all assessment measures, suggesting that she no longer met criteria for PTSD post-treatment. Furthermore, one month post the final treatment session DS reported that her last few low intensity/frequency symptoms had resolved and she considered that she had largely returned to premorbid functioning.

\subsection{Difficulties}

One difficulty experienced in treating DS was in relation to the treating therapist's available appointment times for in prolonged in vivo exposure driving sessions, which required longer than the standard $60 \mathrm{~min}$ treatment sessions. To allow for consistent therapeutic sessions of flexible duration, appointments were made outside of the usual practice hours so as not to disrupt other patient bookings.

DS continued to suffer some mild physical pain in her jaw which did not completely resolve at the end of treatment. A referral to a physiotherapist was recommended to assess and treat as appropriate.

\subsection{Discussion of Practice Issues and Future Development}

Blanchard and Hickling (1997; 2004) found that approximately $55 \%$ of MVA survivors who had acute
PTSD showed spontaneous improvement in symptoms over the first six to eight months and by 12 months approximately $65 \%$ has shown some improvement. Approximately $30 \%$ of survivors still met full criteria for PTSD at 12 months post MVA. This indicates that there is some spontaneous remission for Acute PTSD symptoms over time but a significant number of people continue to suffer psychological symptoms or full diagnostic criteria PTSD and require specific treatment (Blanchard and Hickling, 2004).

DS was treated in the acute stage of PTSD, within 12 weeks but at least eight weeks post MVA. It is possible that if left untreated she may have been one of the potential $65 \%$ referred to above who showed some spontaneous improvement without treatment by 12 months. However, it is also possible and indeed probable that without treatment she would have continued to suffer from some psychological symptoms that would have impacted negatively on her quality of life especially given the level of avoidance that she indicated she was engaging in. This raises the issue of early mental health intervention and whether it is possible to prevent the development of chronic PTSD and its related disabilities.

\section{CONCLUSION}

Based on the high prevalence, chronicity of the symptoms, high comorbidity of psychiatric problems, functional impairment (Khouzam et al., 2005) and estimations of the financial costs (DuPont et al., 1996; Rice and Miller, 1998; Solomon and Davidson, 1997; Wittchen, 2002); it is reasonable to surmise that PTSD causes much personal suffering and is a considerable societal burden. It is therefore paramount that effective treatments continue to be developed and utilised in the treatment of PTSD sufferers. Robust research exists supporting effective treatments for chronic and acute PTSD, however further research on early intervention is warranted to help identify and separate factors that are predictive of resilience and spontaneous recovery, from those predicting a high need for early intervention.

In the case of DS, it is suggestive that early, appropriate evidence-based psychological treatment for acute PTSD was beneficial. The inclusion of EFT in the treatment regimen, although not currently recommended by the world authorities on treating PTSD, was reported by DS as beneficial in quickly decreasing anxiety associated with traumatic memories in the retelling the story narrative and provided another tool for her to manage her hyperarousal when away from session. After six sessions, she no longer met diagnostic criteria for PTSD, nor was she suffering from any post trauma symptoms. Overall, this made a significant positive 
difference to her quality of life and future well-being. Although a single case study has its limitations for its contributions to the evidence base for the treatment of PTSD, these case study results are consistent with the body of research that points to EFT being worthy of further investigation into its efficacy in PTSD treatment and the eventual resolution of its validity or otherwise as a potential evidence based intervention.

\section{REFERENCES}

Adshead, G., 2000. Psychological therapies for posttraumatic stress disorder. Brit. J. Psychiatry, 177: 144-148. DOI: 10.1192/bjp.177.2.144

APA, 2000. Diagnostic and Statistical Manual of Mental Disorders. 4th Edn., American Psychiatric Association, Washington, DC, ISBN-10: 0890420254, pp: 943.

Antony, M.M., P.J. Bieling, B.J. Cox, M.W. Enss and R.P. Swinson, 1998. Psychometric properties of the 42-item and 21-item versions of the Depression Anxiety Stress Scales (DASS) in clinical groups and a community sample. Psychol. Assessment, 10: 176181. DOI: $10.1037 / 1040-3590.10 .2 .176$

ACPMH, 2007. Australian Guidelines for the Treatment of Adults with Acute Stress Disorder and Posttraumatic Stress Disorder. ACPMH.

APS, 2010. Evidence Based Psychological Interventions in the Treatment of Mental Disorders: A Literature Review. 3rd Edn., Australian Psychological Society.

Bahk, W.M., C.U. Pae, J. Tsoh, J.H. Chae and Y.Y. Jun et al., 2002. Effects of mirtazapine in patients with posttraumatic stress disorder in Korea: A pilot study. Human Psychopharmacol., 17: 341-344. DOI: 10.1002/hup.426

Baldwin, D.S., I.M. Anderson, D.J. Nutt, B. Bandelow and B. Bond et al., 2005. Evidence-based guidelines for the pharmacological treatment of anxiety disorders: Recommendations from the British Association for Psychopharmacology. J. Psychopharmacol., 19: 567596. DOI: $10.1177 / 0269881105059253$

Bandelow, B., J. Zohar, E. Hollander, S. Kasper and H.J. Moller et al., 2008. Guidelines for the pharmacological treatment of anxiety, obsessivecompulsive and posttraumatic stress disorders- First Revision. World J. Biolog. Psychiatry, 9: 248-312. DOI: 10.1080/15622970802465807

Beck, J.G. and S.F. Coffey, 2007. Assessment and treatment of PTSD after a motor vehicle collision: Empirical findings and clinical observations. Professional Psychol. Res. Press, 38: 629-639. DOI: 10.1037/0735-7028.38.6.629
Beck, J.G., S.F. Coffey, S.A. Palyo, B. Gudmunddottirm and L.M. Miller et al., 2004. Psychometric properties of the Posttraumatic Cognitions Inventory (PTCI): A replication with motor vehicle accident survivors. Psychol. Assess., 16: 289-298. DOI: 10.1037/1040-3590.16.3.289

Benedek, D.M. and G.H. Wynn, 2011. Clinical Manual for Management of PTSD. 1st Edn., American Psychiatric Pub, Washington D.C., ISBN-10: 1585623598, pp: 468.

Berg, A.O., N. Breslau and M.D. Lezak, 2008. Treatment of Posttraumatic Stress Disorder: An Assessment of the Evidence. 1st Edn., National Academies Press, Washington DC., ISBN-10: 0309109272, pp: 197.

Berger, W., M.V. Mendlowicz, C. Marques-Portella, G. Kinrys and L.F. Fontenelle et al., 2009. Pharmacologic alternatives to antidepressants in posttraumatic stress disorder: A systematic review. Progress Neuropsychopharmacol. Biol. Psychiatry, 33: 169-180. DOI: 10.1016/j.pnpbp.2008.12.004

Bisson, J. and M. Andrew, 2009. Psychological treatments of Post-Traumatic Stress Disorder (PTSD). Cochrane Library.

Bisson, J.I., A. Ehlers, R. Matthews, S. Pilling and D. Richards et al., 2007. Psychological treatment for chronic post-traumatic stress disorder. J. Psychiatry, 190: 97-104. DOI: 10.1192/bjp.bp.106.021402

Blake, D.D., F.W. Weathers, G. Nagy, D.G. Kaloupek and F.D. Gusman et al., 1995. The development of the clinician administered PTSD scale. J. Traumatic Stress, 8: 75-90. DOI: 10.1002/jts. 2490080106

Blake, D.D., F.W. Weathers, L.M. Nagy, D.G. Kaloupek and G. Klauminzer et al., 1990. A clinician rating scale for assessing current and lifetime PTSD: The CAPS-1. Behav. Therapist, 13: 187-188.

Blake, D.D., F.W. Weathers, L.M. Nagy, D. Kaloupek and G. Klauminzer et al., 2000. Clinician-Administered PTSD Scale (CAPS) Instruction Manual. 1st Edn., National Center for PTSD, Boston, MA.

Blanchard, E.B. and E.J. Hickling, 1997. After the Crash: Assessment and Treatment of Motor Vehicle Accident Survivors. 1st Edn., American Psychological Association, Washington DC., ISBN10: 1557984247, pp: 353.

Blanchard, E.B. and E.J. Hickling, 2004. After the Crash: Psychological Assessment and Treatment of Survivors of Motor Vehicle Accidents. 2nd Edn., American Psychological Association, Washington DC., ISBN-10: 1591470706, pp: 475. 
Bonne, O., C. Grillon, M. Vythilingam, A. Neumeister and D.S. Charney, 2004. Adaptive and maladaptive psychobiological responses to severe psychological stress: Implications for the discovery of novel pharmacotherapy. Neurosci. Biobehav. Rev., 28: 65-94. DOI: 10.1016/j.neubiorev.2003.12.001

Bradley, R., J. Greene, E. Russ, L. Dutra and D. Westen, 2005. A multidimensional meta-analysis of psychotherapy for PTSD. Am. J. Psychiatry, 162: 214-217. 10.1176/appi.ajp.162.2.214

Brattberg, G., 2008. Self-administered Emotional Freedom Techniques (EFT) in individuals with fibromyalgia: A randomized trial. Integrat. Med.: A Clin. J., 7: 30-35.

Breslau, N., 2001. The epidemiology of posttraumatic stress disorder: What is the extent of the problem? J. Clin. Psychiatry, 62: 16-22.

Breslau, N., R.C. Kessler and H.D. Chilcoat, 1998. Trauma and posttraumatic stress disorder in the community. Arch. General Psychiatry, 55: 626632. DOI: 10.1001/archpsyc.55.7.626

Briere, J., 2001. Detailed Assessment of Posttraumatic Stress: DAPS: Professional Manual. 1st Edn. Psychological Assessment Resources, Odessa, FL., pp: 56.

Briere, J., 2004. Psychological Assessment of Adult Posttraumatic Stress States: Phenomenology, Diagnosis and Measurement. 2nd Edn., American Psychological Association, Washington DC.

Burke, L. 2010. Single session Emotional Freedom Techniques (EFT) for stress-related symptoms after motor vehicle accidents. Energy Psychol., 2: 65-71.

Cahill, S.P. and E.B. Foa, 2007. Psychological Theroies of PTSD. In: Handbook of PTSD: Science and Practice. Friedman, M., T.M. Keane and P.A. Resick (Eds.), Guilford Press, New York, ISBN10: 1609181743, pp: 55-77.

Cahill, S.P., B.O. Rothbaum, P.A. Resick and V.M. Follette, 2009. Cognitive-Behavioral Therapy for Adults. In: Effective Treatments for PTSD: Practice Guidelines from the International Society for Traumatic Stress Studies. Foa, E.B., T. M. Keane, M.J. Friedman and J.A. Cohen (Eds.), Guilford Press, New York, ISBN-10: 1609181492, pp: 139-222.

Callahan, R. and R. Trubo, 2002. Tapping the Healer Within: Using Though Field Therapy to Instantly Conquer your Fears, Anxieties and Emotional Distress. 1st Edn., McGraw Hill Professional, New York, ISBN-10: 0071394923, pp: 240
Chard, K.M., 2005. Ann evaluation of cognitive processing therapy for the treatment of posttraumatic stress disorder related to childhood sexual abuse. J. Consult. Clin. Psychol., 73: 965971. DOI: 10.1037/0022-006X.73.5.965

Charney, D., 2004. Psychobiological mechanisms of resilience and vulnerability: Implications for successful adaptation to extreme stress. Am. J. Psychiatry, 161: 195-216. DOI: 10.1176/appi.ajp.161.2.195

Chemtob, C.M., R.W. Novaco, R.S. Hamada and D.M. Gross, 1997. Cognitive-behavioural treatment of severe anger in posttraumatic stress disorder. J. Consult. Clin. Psychol., 65: 184-189. DOI: 10.1037/0022-006X.65.1.184

Chossegros, L., M. Hours, P. Charnay, M. Bernard and E. Fort et al., 2011. Predictive factors of chronic posttraumatic stress disorder 6 months after a road traffic accident. Accident Anal. Preventi., 43: 471477. DOI: 10.1016/j.aap.2010.10.004

Church, D., 2013. Clinical EFT as an evidence-based practice foir the treatment of psycholigcal and physiological conditions. Psychology, 4: 645-654. DOI: $10.4236 /$ psych.2013.48092

Church, D. and D. Feinstein, 2013. The Psychobiology and Clinical Principles of Energy Psychology Treatments for PTSD: A Review. In: Psychology of Trauma, Leeuwen, T.V. and M. Brouwer, Nova Science Publishers, Hauppage, NY.

Church, D., C. Hawk, A. Brooks, O. Toukolehto and M. Wren et al., 2013. Psychological trauma symptom improvement in veterans using Emotional Freedom Techniques (EFT): A randomized controlled trial. J. Nervous Mental Disease, 201: 153-160. DOI: 10.1097/NMD.0b013e31827f6351

Church, D., O. Piña, C. Reategui and A. Brooks, 2012. Single session reduction of the intensity of traumatic memories in abused adolescents after EFT: A randomized controlled pilot study. Traumatology, 18: 73-79. DOI: $10.1177 / 1534765611426788$

Cloitre, M., 2009. Effective psychotherapies for posttraumatic stress disorder: A review and critique. CNS Spectr., 14: 32-43. PMID: 19169192

Craig, G., 2008. The EFT Manual. 1st Edn., Energy Psychology Press, Santa Rosa, CA, ISBN-10: 1604150300, pp: 209.

Creamer, M., R. Bell and S. Failla, 2003. Psychometric properties of the impact of event scale-revised. Behav. Res. Therapy, 41: 1489-1496. DOI: 10.1016/j.brat.2003.07.010 
Creamer, M., P. Burgess and A.C. McFarlane, 2001. Post-traumatic stress disorder: Findings from the australian national survey of mental health and wellbeing. Psychol. Med., 31: 1237-1247. DOI: 10.1017/S0033291701004287

Cukor, J., M. Olden, L. Francis and J. Difede, 2010. Evidence-based treatments for PTSD, new directions and special challenges. Ann. New York Acad. Sci., 1208: 82-89. DOI: 10.1111/j.1749-6632.2010.05793.x

Davidson, J., D. Baldwin, D.J. Stein, E. Kuper and I. Benattia et al., 2006a. Treatment of posttraumatic stress disorder with venlafaxine extended release: A 6-month randomized controlled trial. Arch. General Psychiatry, 63: 1158-1165. DOI: 10.1001/archpsyc.63.10.1158

Davidson, J., B.O. Rothbaum, P. Tucker, G. Asnis and I. Benattia et al., 2006b. Venlafaxine extended release in posttraumatic stress disorder: A sertraline-and placebocontrolled study. J. Clin. Psychopharmacol., 26: 259267. DOI: 10.1097/01.jcp.0000222514.71390.c1

Davidson, J.R.T., M.A. Malik and J. Travers, 1997. The Structured Interview for PTSD (SIP): Psychometric validation for DSM-IV criteria. Depression Anxiety, 5: $127-129 . \quad$ DOI: $10.1002 /($ SICI $1520-$ 6394(1997)5:3<127::AID-DA3>3.0.CO;2-B

Davidson, P.R., and K.C.H. Parker, 2001. Eye Movement Desensitization and Reprocessing (EMDR): A metaanalysis. J. Consult. Clin. Psychol., 69: 305-316. DOI: 10.1037/0022-006X.69.2.305

Duffy, M., K. Gillespie and D.M. Clark, 2007. Posttraumatic stress disorder in the context of terrorism and other civil conflict in Northern Ireland: Randomised contolled trial. Brit. Med. J., 334: 11471150. DOI: $10.1136 / \mathrm{bmj} .39021 .846852 . \mathrm{BE}$

DuPont, R.L., D.P. Rice, L.S. Miller, S.S. Shiraki and C.R. Rowland et al., 1996. Economic costs of anxiety disorders. Anxiety, 2: 167-172. DOI: 10.1002/(SICI)1522-7154(1996)2:4<167::AIDANXI2>3.0.CO;2-L

Ehlers, A., D.M. Clark, A. Hackmann, F. McManus and M. Fennell et al., 2003. A randomized controlled trial of cogntive therapy, a self-help booklet and repeated assessment as early interventions for posttraumatic stress disorder. Arch. General Psychiatry, 60: 10241032. DOI: 10.1001/archpsyc.60.10.1024

Elhai, J.D., M.J. Gray, T.B. Kashdan and C.I. Franklin, 2005. Which instruments are most commonly used to assess traumatic event exposure and posttraumatic effects? A survey of traumatic stress professionals. J. Traumatic Stress Stud., 18: 541-545. DOI: $10.1002 /$ jts. 20062
Fang, J., Z. Jin, Y. Wang, K. Li and J. Kong et al., 2009. The salient characteristics of the central effects of acupuncture needling: Limbic-paralimbicneocortical network modulation. Human Brain Mapp., 30: 1196-1206. DOI: 10.1002/hbm.20583

Feinstein, D., 2012. Acupoint stimulation in treating psychological disorders: Evidence of efficacy. Rev. General Psychol., 16: 364-380. DOI: 10.1037/a0028602

Feinstein, D., 2010. Rapid treatment of PTSD: Why psychological exposure with acupoint tapping may be effective. Psychotherapy: Theory Res. Pract., 47: 385-402. DOI: 10.1037/a0021171

First, M.B., 2007. Towards harmonization: An annotated guide to differences in the DSM-IV and ICD-10 definitions of mental disorders. Columbia University.

First, M.B., R.L. Spitzer, M. Gibbon and J.B.W. Williams, 1996. Structures Clinical Interview for the DSM-IV Axis I Disorders, Clinican Version (SCIDCV). 1st Edn., American Psychiatric Press, Washington: DC.

Foa, E.B., 1995. Posttraumatic Stress Diagnostic Scale. 1 st Edn., National Computer Systems, Minneapolis, MN., pp: 49.

Foa, E.B., L. Cashman, L. Jaycox and K. Perry, 1997. The validation of a self report measure of posttraumatic stress disorder: The posttraumatic diagnostic scale. Psychol. Assess., 9: 445-451. DOI: 10.1037/1040-3590.9.4.445

Foa, E.B., C.V. Dancu, E.A. Hembree, L.H. Jaycox and E.A. Meadows et al., 1999. The efficacy of exposure therapy, stress inoculation training and their combination in ameliorating PTSD in female victims of assault. J. Consult. Clin. Psychol., 67: 194-200. DOI: 10.1037/0022-006X.67.2.194

Foa, E.B., A. Ehlers, D.M. Clark, D.F. Tolin and S.M. Orsillo, 1991. The Posttraumatic Cognitions Inventory (PTCI): Development and validation. Psychol. Assess., 11: 303-314. DOI: 10.1037/10403590.11.3.303

Foa, E.B., M.E. Franklin and J. Moser, 2002. Context in the clinic: How well do cognitive-behavioral therapies and medications work in combination? Biol. Psychiatry, 52: 987-997. DOI: 10.1016/S00063223(02)01552-4

Foa, E.B., T.M. Keane, M.J. Friedman and J.A. Cohen, 2009. Effective Treatments for PTSD: Practice Guidelines from the International Society for Traumatic Stress Studies. 2nd Edn., Guilford Press, New York, ISBN-10: 1609181492, pp: 658. 
Foa, E.B., D.S. Riggs, C.V. Dancu and B.O. Rothbaum, 1993. Reliability and validity of a brief instrument for assessing post-traumatic stress disorder. J. Traumatic Stress, 6: 459-473. DOI: 10.1002/jts.2490060405

Foa, E.B. and B.O. Rothbaum, 2001. Treating the Trauma of Rape: Cognitive-Behavioral Therapy for PTSD. 1st Edn., Guilford Press, New York, ISBN10: 1572307366, pp: 286.

Friedman, M.J., 2011. Psychophamacotherapy. In: Clinical Manual for Management of PTSD. Benedek, D.M. and G. H. Wynn (Eds.), American Psychiatric Publishing, Washington DC, ISBN-10: 1585623598, pp: 131-156.

Friedman, M.J. and J.R.T. Davidson, 2010. Pharmacotherapy for PTSD. In: Handbook of PTSD: Science and Practice, Friedman, M., T.M. Keane and P.A. Resick (Eds.), Guilford Press, New York, ISBN-10: 1609181743, pp: 166-190.

Friedman, M.J., J.R.T. Davidson and D.J. Stein, 2009. Psychopharmacotherapy for Adults. In: Effective Treatments for PTSD: Practice Guidelines from the International Society for Traumatic Stress Studies, Foa, E.B., T.M. Keane, M.J. Friedman and J.A. Cohen (Eds.), Guildford Press, New York, ISBN10: 1609181492, pp: 245-268.

Henry, J. and J. Crawford, 2005. The short-form version of the Depression Anxiety Stress Scales (DASS-21): Construct validity and normative data in a large non-clinical sample. Brit. J. Clin. Psychol., 44: 227-239. DOI: 10.1348/014466505X29657

Hetrick, S.E., R. Purcell, B. Garner and R. Parslow, 2010. Combined pharmacotherapy and psychological therapies for Post Traumatic Stress Disorder (PTSD). Cochrane Database Syst. Rev. DOI: 10.1002/14651858.CD007316.pub2

Hickling, E.J. and E.B. Blanchard, 2006. Overcoming the Trauma of Your Motor Vehicle Accident: A Cognitive-Behavioral Treatment Program Therapist Guide: A Cognitive-Behavioral Treatment Program Therapist Guide. Oxford University Press, New York, ISBN-10: 0198041764, pp: 104.

Hickling, E.J., E.B. Blanchard and E. Kuhn, 2005. Brief, early treatment for ASD/PTSD following motor vehicle accidents. Cognit. Behav. Pract., 12: 461-467. DOI: 10.1016/S1077-7229(05)80073-2
Hoge, C.W., D. McGurk, J.L. Thomas, A.L. Cox and C.C. Engel et al., 2008. Mild traumatic brain injury in U.S. soldiers returnng from Iraq. New Engl. J. Med., 358: 453-463. DOI: 10.1056/NEJMoa072972

ISTSS, 2009. Effective treatments for PTSD: Practice guidelines from the International Society for Traumatic Stress Studies. International Society for Traumatic Stress Studies.

Ipser, J.C. and D.J. Stein, 2012. Evidence-based pharmacotherapy of Post-Traumatic Stress Disorder (PTSD). Int. J. Neuropsychopharmacol., 15: 825-840. DOI: 10.1017/S0033291714000853

Iverson, K.M., K. Lester and P.A. Resick, 2011. Psychosocial Treatments. In: Clinical Manual for Management of PTSD, Benedek, D.M. and G.H. Wynn (Eds.), American Psychiatric Publishing, Arlington, VA., ISBN-10: 1585623598, pp: 157203.

Janoff-Bulman, R., 1989. Assumptive worlds and the stress of traumatic events: Applications of the schema construct. Soc. Cognit., 7: 113-136. DOI: 10.1521/soco.1989.7.2.113

Janoff-Bulman, R., 1992. Shattered Assumptions: Towards a New Psychology of Trauma. 1st Edn., Free Press, New York.

Jones, S., J. Thornton and H. Andrews, 2011. Efficacy of Emotional Freedom Techniques (EFT) in reducing public speaking anxiety: A randomized controlled trial. Energy Psychol. Theory, Research Treat., 3: 19-32.

Karatzias, T., K. Power, K. Brown, T. McGoldrick and M. Begum et al., 2011. A controlled comparison of the effectiveness and efficiency of two psychological therapies for post-traumatic stress disorder: Eye movement desensitization and reprocessing vs. emotional freedom techniques. J. Nervous Mental Dis., 199: 372-378. DOI: 10.1097/NMD.0b013e31821cd262

Kessler, R.C., A. Sonnega, E. Bromet, M. Hughes and C.B. Nelson, 1995. Posttraumatic stress disorder in the national comorbidity survey. Arch. General Psychiatry, 52: 1048-1060. DOI: 10.1001/archpsyc.1995.03950240066012

Khouzam, H.R., B. Ghafoori and R. Hierholzer, 2005. Progress in the Identification, Diagnosis and Treatment of Posttraumatic Stress Disorder. In: Trends in Posttraumatic Stress Disorder Research, Corales, T.A. (Ed.) Nova Science, New Jersey, ISBN-10: 1594541353, pp: 1-28. 
Kim, W., C.U. Pae, J.H. Chae, T.Y. Jun and and W.M. Bahk, 2005. The effectiveness of mirtazapine in the treatment of posttraumatic stress disorder: a 24week continuation therapy. Psychiatry Clin. Neurosc., 59: 743-747. DOI: 10.1111/j.14401819.2005.01447.x

Lovibond, S.H. and P.F. Lovibond, 1996. Manual for the Depression Anxiety Stress Scales. 2nd Edn., Psychology Foundation of Australia, Sydney Australia, ISBN-10: 0733414230, pp: 42.

Marks, I., K. Lovell, H. Noshirvani, M. Livanou and S. Thrasher, 1998. Treatment of posttraumatic stress disorder by exposure and/or cognitive restructuring: A controlled study. Arch. General Psychiatry, 55: 317-25. DOI: 10.1001/archpsyc.55.4.317

Mayou, R.A., 2002. Psychiatric consequences of motor vehicle accidents. Psychiatric Clinics North Am., 25: 27-41. DOI: 10.1016/S0193-953X(03)00051-0

Monson, C.M., P.P. Schnurr, P.A. Resick, M.J. Friedman and Y. Young-Xu et al., 2006. Cognitive processing therapy for veterans with military-related posttraumatic stress disorder. J. Consult. Clin. Psychol., 74: 898-907. DOI: 10.1037/0022006X.74.5.898

Najavits, L.M., 2002. Psychosocial Treatments of Posttraumatic Stress Disorder. In: A Guide to Treatments that Work, Nathan, P.E. and J.M. Gorman (Eds.), Oxford University Press, New York, ISBN-10: 0199760985, pp: 704-704.

NICE, 2005. Clinical Guideline 26 Post-Traumatic Stress Disorder (PTSD): The Management of PTSD in Adults and Children in Primary and Secondary Care. National Institute of Clinical Excellence, London.

Newman, E., D.G. Kaloupek and T.M. Keane, 1996. Assessment of Posttraumatic Stress Disorder in Clinical and Research Settings. In: Traumatic Stress, Van Der Kolk, B.A., A.C. McFarlane and L. Weisaeth (Eds.), Guilford Press, New York, pp: 242-275.

Ng, F., T. Trauer, S. Dodd, T. Callaly and S. Campbell et $a l ., 2007$. The validity of the 21 -item version of the Depression Anxiety Stress Scales as a routine clinical outcome measure. Acta Neuropsychiatrica, 19: $\quad 304-310$. DOI: $10.1111 / \mathrm{j} .1601-$ 5215.2007.00217.x

Norris, F.H., 1992. Epidemiology of trauma: Frequency and impact of differnt potentially traumatic events on different demographic groups. J. Consult. Clin. Psychol., 60: 409-418. DOI: 10.1037/0022-006X.60.3.409
Neumeister, A., S. Henry and J.H. Krystal, 2007. Neurocircuitry and neuroplasticity in PTSD. In: Handbook of PTSD: Science and Practice, Friedman, M., T.M. Keane and P.A. Resick (Eds.), Guilford Press, New York, pp: 151-165.

Page, A.C. and W.G.K. Stritzke, 2006. Clinical Psychology for Trainees: Foundations of ScienceInformed Practice. 1st Edn., Cambridge University Press, Cambridge, UK., ISBN-10: 1139457381.

Ponniah, K. and S.D. Hollon, 2009. Empirically supported psychological treatments for adult acute stress disorder and posttraumatic stress disorder: A review. Depression Anxiety, 26: 1086-1109. DOI: 10.1002/da.20635

Rice, D.P. and L.S. Miller, 1998. Health economics and cost implications of anxiety and other mental disorders in the United States. Br. J. Psychiatry Suppl. PMID: 9829010

Resick, P.A., T.E. Galovski, M.O. Uhlmansiek, C.D. Scher and G.A. Clum et al., 2008. A randomized clinical trial to dismantle components of cognitive processing therapy for posttraumatic stress disorder in female victims of interpersonal violence. J. Consult. Clin. Psychol., 76: 243-258. DOI: 10.1037/0022-006X.76.2.243

Resick, P.A., P. Nishith, T.L. Weaver, M.C. Astin and C.A. Feurer, 2002. A comparison of of cogitiveprocessing therapy with prolonged exposure and a waiting condition for the tretament of chronic posttraumatic stress disorder in female rape victims. J. Consult. Clin. Psychol., 70: 867-879. DOI: 10.1037/0022-006X.70.4.867

Resick, P.A., M.K. Schinke and B.G. Markway, 1991. The Relationship Between Cognitive Content and Posttraumatic Stress Disorder. 1st Edn., New York.

Roberts, N.P., N.J. Kitchener, J. Kenardy and J.I. Bisson, 2009a. Multiple session early psychological interventions for the prevention of post-traumatic stress disorder. Cochrane Database Syst. Rev. DOI: 10.1002/14651858.CD006869.pub2

Roberts, N.P., N.J. Kitchener, J. Kenardy and J.I. Bisson, 2009b. Systematic review and meta-analysis of multiple-session early interventions following traumatic events. Am. J. Psychiatry, 166: 293-301. DOI: 10.1176/appi.ajp.2008.08040590

Roberts, N.P., N.J. Kitchener, J. Kenardy and J.I. Bisson, 2010. Early psychological interventions to treat acute traumatic stress symptoms. Cochrane Database Syst. Rev., DOI: 10.1002/14651858.CD007944.pub2 
Rothbaum, B.O., M.C. Kearns, M. Price, E. Malcoun and M. Davis et al., 2012. Early intervention may prevent the development of posttraumatic stress disorder: A randomised pilot civilian study with modified prolonged exposure. Biol. Psychiatry, 72: 957-963. DOI: 10.1016/j.biopsych.2012.06.002

Rubin, A., 2007. A Practitioners Guide to Using Research for Evidence Based Practice. 1st Edn., John Wiley and Sons, New York.

Sakai, C.S., S.M. Connolly and P. Oas, 2010. Treatment of PTSD in Rwandan child genocide survivors using thought field therapy. Int. J. Emergency Mental Health, 12: 41-50. PMID: 20828089

Salas, M.M., A.J. Brooks and J.E. Rowe, 2011. The immediate effect of a brief energy psychology intervention (Emotional Freedom Techniques) on specific phobias: A pilot study. Explore: J. Sci. Heal., 7: 255-260. DOI: 10.1016/j.explore.2011.02.005

Schottenbauer, M.A., C.R. Glass, D.B. Arnoff, V. Tendick and S.H. Gray, 2008. Nonresponse and dropout rates in outcome studies on PTSD: Review and methodological considerations. Psychiatry, 71: 134-168. DOI: 10.1521/psyc.2008.71.2.134

Sezgin, N. and B. Özcan, 2009. The effect of progressive muscular relaxation and emotional freedom techniques on test anxiety in high school students: A randomized controlled trial. Energy Psychol. Theory Res. Treat., 1: 23-30.

Sharp, T.J. and A.G. Harvey, 2001. Chronic pain and posttraumatic stress disorder: Mutual maintenance. Clin. Psychol. Rev., 24: 857-877. DOI: 10.1016/S0272-7358(00)00071-4

Shea, M.T., M. McDevitt-Murphy, D.J. Ready and P.P. Schnurr, 2009. Group Therapy. In: Effective Treatments of PTSD: Practice Guidelines from the International Society for Traumataic Stress Studies, Foa, E.B., T.M. Keane, M.J. Friedman and J.A. Cohen (Eds.), Guilford Press, New York, pp: 306-326.

Solomon, S.D. and J.R. Davidson, 1997. Trauma: Prevalence, impairment, service use and cost. J. Clin. Psychiatry, 58: 1-11. PMID: 9329445

Southwick, S.M., L.L. Davis, D.E. Aikins, A. Rasumusson and J. Barron et al., 2007. Neurobiological Alterations Associated with PTSD. In: Handbook of PTSD: Science and Practice, Friedman, M., T.M. Keane and P.A. Resick, (Eds.), Guilford Press, New York, pp: 166-190.

Spitzer, R.L., M.B. First and J.C. Wakefield, 2007. Saving PTSD from itself in DSM-V. J. Anxiety Disorders, 21: 233-241. DOI: 10.1016/j.janxdis.2006.09.006
Spates, C.R., E. Koch, K. Cusack, S. Pagoto and S. Waller, 2009. Eye Movement Desensitization and Reprocessing. In: Effective Treatments for PTSD: Practice Guidelines from the International Society of Traumatic Stress Studies, Foa, E.B., T.M. Keane, M.J. Friedman and J.A. Cohen (Eds.), Guilford Press, New York, pp: 279-305.

Stahl, S.M., M.M. Grady, C. Moret and M. Briley, 2005. SNRIs: Their pharmacology, clinical efficacy and tolerability in comparison with other classes of Antidepressants. CNS Spectrums, 10: 732-747. PMID: 16142213

Stapleton, P., D. Church, T. Sheldon, B. Porter and C. Carlopio, 2013. Depression symptoms improve after successful weight loss with Emotional Freedom Techniques (EFT): A randomized controlled trial. IRSN Psychiatry, 2013: 573532573538. DOI:10.1155/2013/573532.

Stapleton, P., T. Sheldon, B. Porter and J. Whitty, 2011. A randomised clinical trial of a meridian-based intervention for food cravings with a six-month follow-up. Behav. Change, 28: 1-16.

Stapleton, P., T. Sheldon and B. Porter, 2012. Clinical benefits of emotional freedom techniques on food cravings at 12-months follow-up: A randomized controlled trial. Energy Psychol. J., 4: 13-24.

Stein, D.J., J. Ipser and N. McAnda, 2009. Pharmacotherapy of posttraumatic stress disorder: A review of meta-analyses and treatment guidelines. CNS Spectrums, 14: 25-31. PMID: 19169191

Stein, M.B. and T.W. McAllister, 2009. Exploring the convergence of posttraumatic stress disorder and mild traumatic brain injury. Am. J. Psychiatry, 166: 768-776. DOI: 10.1176/appi.ajp.2009.08101604

Sundin, E.C. and M.J. Horowitz, 2002. Impact of Event Scale: Psychometric properties. Br. J. Psychiatry, 180: 205-209. DOI: 10.1192/bjp.180.3.205

Tarrier, N., H. Pilgrim, C. Sommerfield, B. Faragher and M. Reynolds et al., 1999. A randomized trial of cognitive therapy and imaginal exposure in the treatment of chronic posttraumatic stress disorder. J. Consult. Clin. Psychol., 67: 13-18. DOI: 10.1037/0022-006X.67.1.13

VA/DoD, 2010. Clinical practice guideline for the management of posttraumatic stress. Veterans Health Administration and Department of Defense Washington DC,

Vogt, D.S., D.W. King and L.A. King, 2007. Risk Pathways for PTSD. In: Handbook of PTSD: Science and Practice, Friedman, M., T. Keane and P. Resick (Eds.), Guilford Press, New York, pp: 99-115. 
Weathers, F.W., T.M. Keane and E. Foa, 2009. Assessment and Diagnosis of Adults. In: Effective Treatments for PTSD: Practice Guidelines from the International Society of Traumatic Stress Studies, Foa, E.B., T.M. Keane, M.J. Friedman and J.A. Cohen (Eds.),. Guilford Press, New York, pp: 23-61. Weathers, F.W., B.T. Herman, D.S. Litz, J.A. Huska and T.M. Keane, 1993. The PTSD Checlist (PCL): Relaibility, validity and diagnsotic utility. International Society for Tarumatic Stress Studies, San Antonia, TX.

Weiss, D.S. and C.R. Marmar, 1997. The Impact of Event Scale-Revised. In: Assessing Psychological Trauma and PTSD, Wison, J.P. and T.M. Keane (Eds.), Guilford Press, New York, pp: 399-411.
Wittchen, H.U., 2002. Generalized anxiety disorder: Prevalence, burden and cost to society. Depression Anxiety, 16: 162-171. DOI: 10.1002/da.10065

Wolpe, J., 1991. Practice of Behavior Therapy. 4th Edn., Allyn and Bacon, Incorporated, ISBN-10: 0205145159, pp: 448.

WHO, 1992. The ICD-10 classification of Mental and Behavioural Disorders: Clinical Descriptions and Diagnostic Guidelines. 10th Edn., WHO, ISBN-10: 9241544228, pp: 362.

Yehuda, R. and A.C. McFarlane, 1995. Conflict between current knowledge about posttraumatic stress disorder and its original conceptual basis. Am. J. Psychiatry, 152: 1705-1713. PMID: 8526234

Appendix A

Session Rating Scale (SRS V.3.0)

\begin{tabular}{|lr||}
\hline Name & Age (Yrs): \\
ID\# & Sex: M / F \\
Session \#__ Date: $\_$ \\
\end{tabular}

Please rate today's session by placing a mark on the line nearest to the description that best fits your experience.

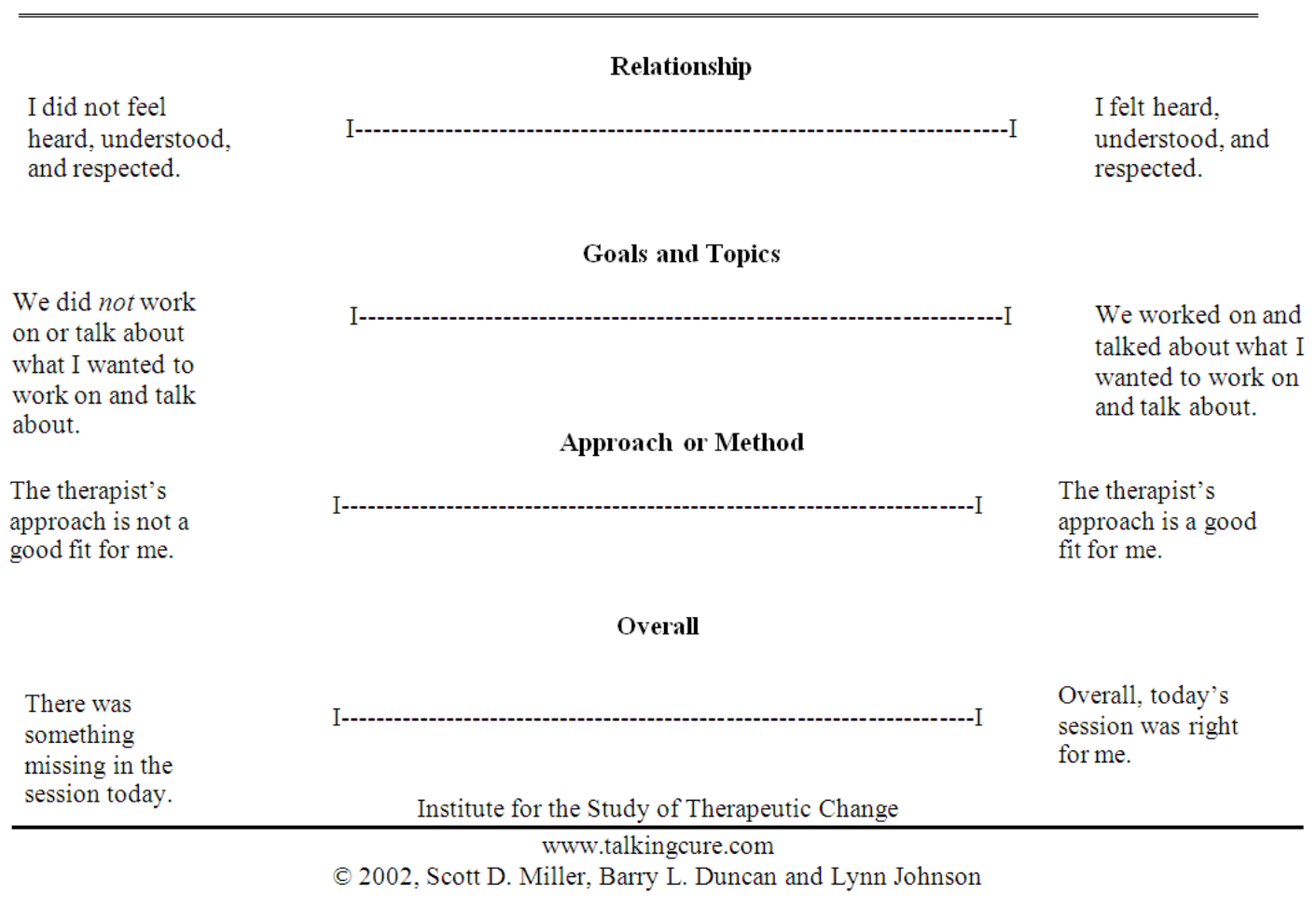


Terri Sheldon / Current Research in Psychology 5 (1): 40-63, 2014

Appendix B

Automatic Thoughts Form

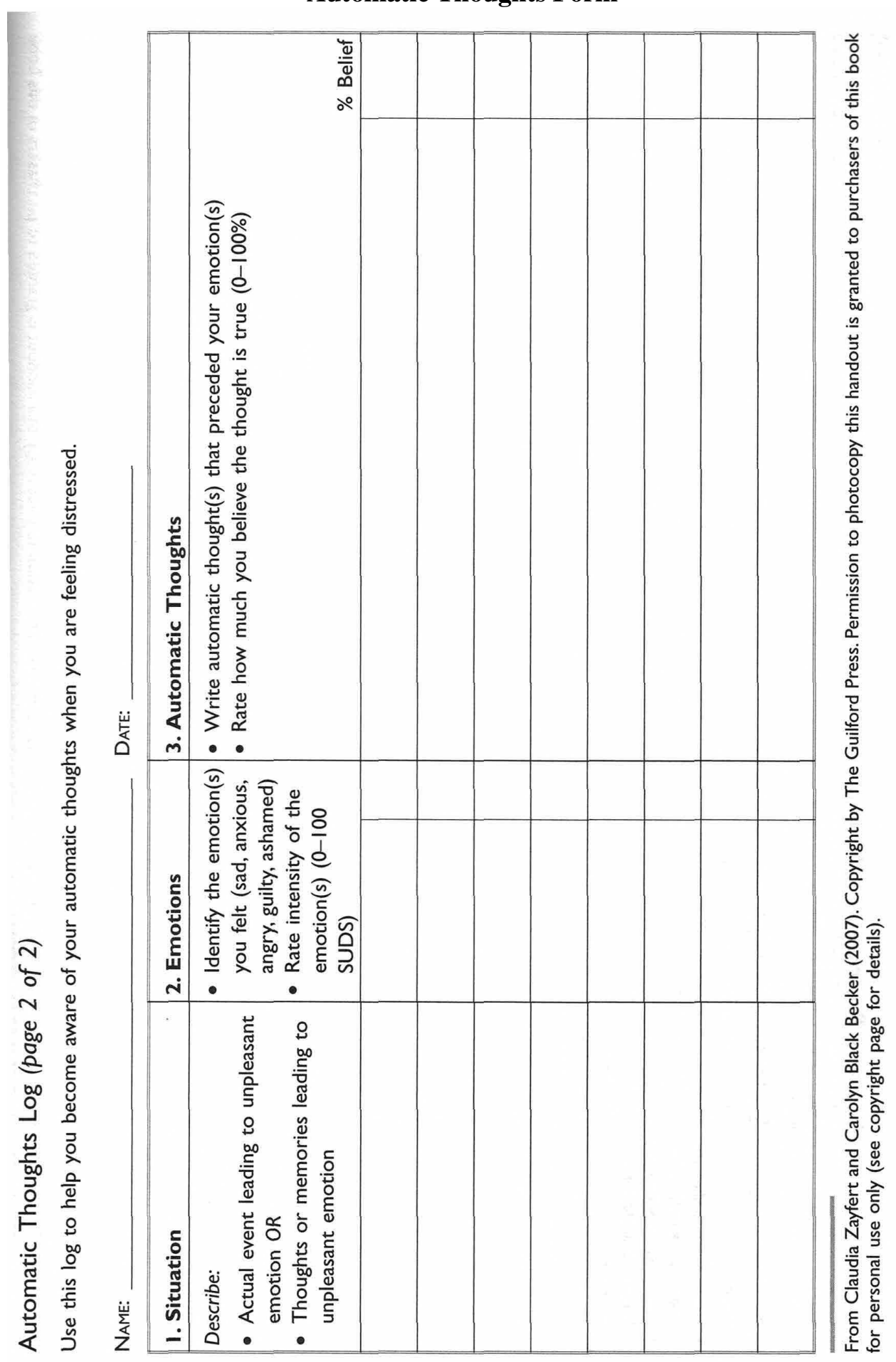




\section{Appendix C}

\section{Reliable and Clinical Change Calculations for DASS-21 Anxiety Subscale}

Study Details

Study / Client Identifier: Mrs E 2012

Assessment Details: pre to post tx

Measurement Device: DASS21- Anxiety subscale

Time 1 Score: 16

Time 2 Score: 0

Test-retest reliability of measurement device: 0.88

Standard deviation of sample used to estimate reliability of device: 8.12

Clinical Sample Mean: 10.9

Clinical Sample Standard Deviation: 8.12

Normal Sample Mean: 4.7

Normal Sample Standard Deviation: 4.91

Standard error of measurement: 2.81285 Standard error of the difference: 3.97797

In order to change with: $68.26 \%$ confidence $(1 \mathrm{sd})$, there must be a change of at least: $3.97895 \%$ confidence $(1.96 \mathrm{sd})$, there must be a change of at least: 7.79668 $99 \%$ confidence $(2.58 \mathrm{sd})$, there must be a change of at least: 10.24658

Your client's score of - 16 suggests that he / she: HAS changed with at least $68.26 \%$ confidence. HAS changed with at least $95 \%$ confidence. HAS changed with at least $99 \%$ confidence.

\section{Clinical Cut-Offs}

This Programme has computed that:

It appears that clinical samples score higher.

Therefore, a decrease in scores over time equates to improvement. This programme has made the necessary adjustments to the clinical change computations.

\section{A). 1.96 standard deviations away from the clinical} mean is: -5.0152

So, has the client reliably changed (with at least 95\% confidence) AND changed from being within 1.96 standard deviations of the clinical mean to now being 1.96 standard deviations away from the clinical mean?

\section{Some Criteria Were Not Met}

B). 1.96 standard deviations away from the normal mean is: 14.3236

So, has the client reliably changed (with at least 95\% confidence) AND changed from being more than 1.96 standard deviations away the normal mean to now being within 1.96 standard deviations of the normal mean?

\section{YES}

C). Mid-way between the clinical and normal distributions is: 7.0363

So, has the client reliably changed (with at least 95\% confidence) AND changed clinical status according to the intersection of the clinical and normal distributions?

YES

\section{Appendix D}

\section{Reliable and Clinical Change Calculations for DASS-21 Depression Subscale}

Study Details

Study / Client Identifier: Mrs E 2012

Assessment Details: pre to post tx

Measurement Device: DASS21- Depression subscale

Time 1 Score: 8

Time 2 Score: 2

Test-retest reliability of measurement device: 0.88

Standard deviation of sample used to estimate reliability of device: 9.3

Clinical Sample Mean: 10.65

Clinical Sample Standard Deviation: 9.3

Normal Sample Mean: 6.34

Normal Sample Standard Deviation: 6.97

Standard error of measurement: 3.22161 Standard error of the difference: 4.55605

In order to change with: $68.26 \%$ confidence ( $1 \mathrm{sd})$, there must be a change of at least: $4.55695 \%$ confidence $(1.96 \mathrm{sd})$, there must be a change of at least: 8.9297 $99 \%$ confidence $(2.58 \mathrm{sd})$, there must be a change of at least: 11.73561

Your client's score of -6 suggests that he / she: HAS changed with at least $68.26 \%$ confidence. Has NOT changed with at least $95 \%$ confidence. Has NOT changed with at least $99 \%$ confidence. Clinical Cut-Offs

This Programme has computed that:

It appears that clinical samples score higher.

Therefore, a decrease in scores over time equates to improvement. This programme has 
made the necessary adjustments to the clinical change computations.

\section{A). 1.96 standard deviations away from the clinical mean is: -7.578}

So, has the client reliably changed (with at least 95\% confidence) AND changed from being within 1.96 standard deviations of the clinical mean to now being 1.96 standard deviations away from the clinical mean?

\section{Some Criteria Were Not Met}

B). 1.96 standard deviations away from the normal mean is: 20.0012

So, has the client reliably changed (with at least 95\% confidence) AND changed from being more than 1.96 standard deviations away the normal mean to now being within 1.96 standard deviations of the normal mean?

\section{Some Criteria Were Not Met}

C). Mid-way between the clinical and normal distributions is: 8.18639 So, has the client reliably changed (with at least $95 \%$ confidence) AND changed clinical status according to the intersection of the clinical and normal distributions?

\section{Some Criteria Were Not Met}

\section{Appendix E}

Study Details

\section{Reliable and Clinical Change Generator}

Study / Client Identifier: Mrs E 2012

Assessment Details: pre to post tx

Measurement Device: DASS21- Stress subscale

Time 1 Score: 22

Time 2 Score: 6

Test-retest reliability of measurement device: 0.88

Standard deviation of sample used to estimate reliability of device: 11.15

Clinical Sample Mean: 21.1

Clinical Sample Standard Deviation: 10.15

Normal Sample Mean: 10.11

Normal Sample Standard Deviation: 7.91

Standard error of measurement: 3.86247 Standard error of the difference: 5.46236

In order to change with: $68.26 \%$ confidence $(1 \mathrm{sd})$, there must be a change of at least: $5.46295 \%$ confidence $(1.96 \mathrm{sd})$, there must be a change of at least: 10.70603 $99 \%$ confidence $(2.58 \mathrm{sd})$, there must be a change of at least: 14.07011

Your client's score of -16 suggests that he / she: HAS changed with at least $68.26 \%$ confidence. HAS changed with at least $95 \%$ confidence. HAS changed with at least $99 \%$ confidence.

Clinical Cut-Offs

This Programme has computed that:

It appears that clinical samples score higher.

Therefore, a decrease in scores over time

equates to improvement. This programme has

made the necessary adjustments to the clinical

change computations.

A). 1.96 standard deviations away from the clinical mean is: 1.206

So, has the client reliably changed (with at least 95\% confidence) AND changed from being within 1.96 standard deviations of the clinical mean to now being 1.96 standard deviations away from the clinical mean?

\section{Some Criteria Were Not Met}

B). 1.96 standard deviations away from the normal mean is: 25.6136

So, has the client reliably changed (with at least 95\% confidence) AND changed from being more than 1.96 standard deviations away the normal mean to now being within 1.96 standard deviations of the normal mean?

\section{Some Criteria Were Not Met}

C). Mid-way between the clinical and normal distributions is: 14.92345 So, has the client reliably changed (with at least $95 \%$ confidence) AND changed clinical status according to the intersection of the clinical and normal distributions?

\section{YES}

